NBER WORKING PAPER SERIES

\title{
THE EFFECTS OF INCOME MOBILITY AND TAX PERSISTENCE ON INCOME REDISTRIBUTION AND INEQUALITY
}

\author{
Marina Agranov \\ Thomas R. Palfrey \\ Working Paper 22759 \\ http://www.nber.org/papers/w22759 \\ NATIONAL BUREAU OF ECONOMIC RESEARCH \\ 1050 Massachusetts Avenue \\ Cambridge, MA 02138 \\ October 2016
}

We thank Michael McBride and the staff of the Experimental Social Science Laboratory (ESSL) at UC Irvine for their support and for granting access to the laboratory and subject pool. We thank the Hacker Social Science Experimental Laboratory (SSEL) at Caltech for supporting the software development for the experiment. We gratefully acknowledge the financial support of the National Science Foundation (SES-1426560), the Gordon and Betty Moore Foundation (SES-1158), and the Russell Sage Foundation. The views expressed herein are those of the authors and do not necessarily reflect the views of the National Bureau of Economic Research.

NBER working papers are circulated for discussion and comment purposes. They have not been peer-reviewed or been subject to the review by the NBER Board of Directors that accompanies official NBER publications.

(C) 2016 by Marina Agranov and Thomas R. Palfrey. All rights reserved. Short sections of text, not to exceed two paragraphs, may be quoted without explicit permission provided that full credit, including $\odot$ notice, is given to the source. 
The Effects of Income Mobility and Tax Persistence on Income Redistribution and Inequality Marina Agranov and Thomas R. Palfrey

NBER Working Paper No. 22759

October 2016

JEL No. C92,D3,H2

\begin{abstract}
$\underline{\text { ABSTRACT }}$
We explore the effect of income mobility and the persistence of redistributive tax policy on the level of redistribution in democratic societies. An infinite-horizon theoretical model is developed, and the properties of the equilibrium tax rate and the degree of after-tax inequality are characterized. Mobility and stickiness of tax policy are both negatively related to the equilibrium tax rate. However, neither is sufficient by itself. Social mobility has no effect on equilibrium taxes if tax policy is voted on in every period, and tax persistence has no effect in the absence of social mobility. The two forces are complementary. Tax persistence leads to higher levels of posttax inequality, for any amount of mobility. The effect of mobility on inequality is less clear-cut and depends on the degree of tax persistence. A laboratory experiment is conducted to test the main comparative static predictions of the theory, and the results are generally supportive.
\end{abstract}

\author{
Marina Agranov \\ California Institute of Technology \\ 228-77 Caltech \\ Pasadena, CA 91125 \\ magranov@hss.caltech.edu \\ Thomas R. Palfrey \\ Division of Humanities and Social Sciences \\ 228-77 Caltech \\ Pasadena, CA 91125 \\ and NBER \\ trp@hss.caltech.edu
}




\section{Introduction}

Tax rates vary a great deal across countries, and even across states within countries. It is important for a variety of policy reasons to understand why and to untangle the many possible sources of this wide variation. One potentially important source of variation that has received considerable attention from economists is social mobility. Income taxation, by design, is redistributive in two senses. First, public goods provided by the tax revenues - such as free education, clean water, fresh air, fire and police protection, and national defense - generate a distribution of benefits that is roughly equal across income groups, or at least far less skewed than the distribution of income. Second, tax revenues are also used for income-tested policies that have direct redistributional consequences, such as food stamps, medical insurance subsidies, and cash grants. Because of the key redistributional effects of taxation, one might expect that in more-mobile societies, or in societies in which considerable upward mobility is expected, poor and middle class voters may favor relatively lower tax rates than they would if there were no tomorrow. One may be on the low end of the income scale today - where higher tax rates are helpful - but have beliefs (realistic or otherwise) of being considerably higher on the income scale tomorrow, in which case lower tax rates would be better.

An underlying premise for this intuition, and one that is widely accepted as a stylized fact, is that redistributive tax policy is relatively "sticky." That is, in modern democratic institutions, income tax rates are very difficult to change once they are in place, except for relatively minor adjustments. So it is the combination of the persistence of unchanged tax rates over many years and expectations of upward mobility that dampens voter preferences for redistribution. This is called the prospect of upward mobility (POUM) hypothesis (Benabou and Ok, 2001). While the prospect of upward mobility, in principle, can work in the opposite direction - that is, rich voters preferring higher taxes to insure their potential downward mobility - in a majoritarian political system, at least theoretically, it is the median voter's tax preferences that determine the equilibrium tax rate. As long as the median voter's income is less than the average income among the electorate (an essentially universal empirical fact), the overall effect of income mobility on equilibrium tax rates will result in lower income tax rates than in the absence of income mobility.

This paper proposes and analyzes an infinite-horizon model of equilibrium tax rates to explore the effects of stochastic income mobility and tax persistence, allowing for both upward and downward mobility. As far as we know, this is the first dynamic version

of the classic models of Romer (1975), Roberts (1977) and Meltzer and Richard (1981). 
The environment is characterized by a fixed distribution of wage rates in the population. Initially, each individual in the economy is endowed with a wage rate that is drawn from this distribution. The initial linear tax rate, $t$, is determined by a competitive political process that yields the median voter's ideal tax rate for that period. Each individual chooses her labor supply optimally, given her wage and the tax rate, and pays fraction $t$ of her income in taxes. The aggregate taxes that are collected are then redistributed equally to all individuals. Labor supply is increasing in wage and decreasing in the tax rate, capturing the distortive nature of taxation. In each subsequent period, with some fixed probability, $\alpha$, wage rates are randomly reassigned using the same distribution of wages, which generates the stochastic process governing income mobility. Also in each subsequent period, with probability $p$, the previous period's tax rate remains unchanged, and with probability $1-p$, a new vote over tax rates is taken, which generates the stochastic process governing tax persistence. Individuals are assumed to have correct expectations about the stochastic process driving income mobility transitions and tax persistence, and we characterize the equilibrium tax rate as a function of the parameters governing the income mobility process. Individual induced preferences over the current period's tax rate are obtained by solving a system of stochastic infinite-horizon dynamic programs with discounting. We prove that these induced preferences are single-peaked, which guarantees the existence of a unique majority rule equilibrium tax rate. The equilibrium income tax rate declines monotonically in the mobility and tax persistence parameters and the discount factor, and it increases with wage inequality.

We also characterize the effect of mobility and tax persistence on after-tax inequality. For any degree of mobility, greater stickiness of the tax policy (i.e., persistence) leads to higher long-run inequality, as measured by the variance of the discounted value of the infinite stream of after-tax income. The effect of an increase in income mobility on longrun inequality is more complicated and depends on tax persistence. If tax persistence is sufficiently high, then greater income mobility increases inequality. The opposite is true if tax rates are revised frequently. The reason is that there are two opposing effects of increasing mobility: on the one hand, mobility mechanically decreases inequality for any fixed tax rate; on the other hand, the equilibrium effect of higher mobility reduces the tax rate, which leads to greater inequality. Because inequality is increasing in tax persistence, the second effect dominates the first if tax rates are revised infrequently. The comparative statics with respect to efficiency, as measured by total income, are exactly the opposite, so there is a long-run efficiency-equity tradeoff in our model.

The second half of the paper reports the design and results of a laboratory experi- 
ment implementing a simplified two-period environment that captures the most relevant features of the theoretical model - in particular, sharing the same comparative statics with respect to tax persistence and stochastic income mobility. The design uses multiple treatments that allow us to compare the observed tax rates under different parameters governing tax persistence and income mobility. There are four treatments. In treatment one, there is no mobility and no tax persistence. Treatment two also has no tax persistence, but there is an intermediate level of mobility between the two periods. The other two treatments both have full tax persistence (i.e., the tax rate voted in period 1 remains in place in period 2). Treatment three uses the same level of mobility as in treatment two, and treatment four uses the highest possible level of mobility. Comparing the first two treatments allows us to test the theoretical direct effect of income mobility on the level of taxes (no effect) and the level of inequality (mobility reduces inequality) when taxes are not persistent. Comparing treatments two and three allows us to to test the effect of tax persistence on equilibrium tax rates (persistence reduces taxes) and inequality (persistence increases inequality), holding fixed the level of income mobility. Comparing treatments three and four allows us to test the effect of very high levels of income mobility on equilibrium tax rates (high mobility reduces taxes relative to intermediate levels) and inequality (high mobility increases inequality relative to intermediate levels) when taxes are persistent.

One might plausibly wonder how a laboratory experiment could be relevant to understanding something as complex as the effect of income mobility and tax persistence on redistributive tax policy. There already exist a number of empirical political economy studies that attempt to assess the validity of the hypothesis that social mobility and persistent taxes will lower taxes and possibly have a negative impact on income inequality. While some broad support is found for these effects, the estimates of their magnitude vary wildly (across countries and across time) and, more importantly, are plagued with measurement issues since researchers can only coarsely control for confounding factors. Moreover, none of these studies controls for tax persistence, which is a key variable from the theoretical perspective. All the studies are based on survey data about preferences for redistribution. The strongest findings indicate that there is a negative relationship between subjectively perceived probabilities of upward mobility, as elicited by survey methods, and preferences for redistribution from the rich to the poor. There is relatively little support for the hypothesis that there is a relationship between general mobility indices and preferences for redistribution. ${ }^{1}$ To our knowledge, there is no empirical study

\footnotetext{
${ }^{1}$ See, for example, the Checchi and Dardanoni (2002) study of occupational and social prestige mobility
} 
that explores a causal link between income or social mobility and redistributive policy, which is the focal point of the present study. Rather, all the existing studies focus on identifying correlations between self-reported mobility and survey responses to qualitative questions related to redistribution from the rich to the poor.

Laboratory experiments, by implementing an especially simple environment to which theory is expected to apply, offer a clean methodology for directly testing the effects of the theoretical parameters driving social mobility and the implemented level of redistribution. Our experiment allows us to examine the effect of mobility on post-tax inequality. This is very difficult to accomplish with field data because there are two confounding effects. On the one hand, mobility has a mechanical effect that reduces inequality. If some of today's poor may become rich tomorrow, and vice versa, then one's overall pretax income across the two periods is going to be less dispersed than if there were no mobility. On the other hand, the existence of social mobility in the population leads to lower equilibrium tax rates, which increases inequality. The theory provides a framework for comparing the relative magnitudes of these opposing forces, and the experiment allows us to measure them and compare these measurements with the theory. Not only can the qualitative comparative statics be tested, but our laboratory experiment allows for a quantitative evaluation of the magnitudes of the effects that are predicted by theory. It also allows for the possibility of clear rejections of the basic theory. If the theoretical predictions fail in the simplest and most transparent version of the model, then that casts serious doubt on the usefulness of the theory for application to complex economies and political systems, the properties of which the field of political economy seeks to understand.

The experiment we report here contributes to a better understanding of these effects. The design uses multiple treatments that allow for a stark comparison of voter tax preferences and implemented tax rates under different assumptions about the persistence of tax policy and different expectations about income mobility. The experiment produced three main findings. First, the tax levels observed in the first two treatments are not significantly different from each other. Thus, if tax policy is not persistent but, rather, is set by a majority rule process in every period, then implemented tax rates are unaffected by income mobility and income mobility decreases inequality, as predicted by the the-

in Italy, which finds that the results are very sensitive to the choice of index. Alesina and La Ferrara (2005) construct a different index from the PSID, which has somewhat more explanatory power, and apply it to a state-level analysis of mobility and redistributive preferences in the US. Ravallion and Loshkin (2000) find survey evidence connecting perceived mobility and preferences for redistribution, but, again, there is a disconnect between perceived and actual mobility. Rainer and Siedler (2008) also find similar survey evidence for Germany, but their survey question addresses the progressivity of taxation rather than the overall level of taxes. 
ory. Second, comparing treatments two and three, we find that mobility has a negative effect on the tax level and, thus, leads to greater post-tax income inequality. We find no significant difference in tax rates between treatment three (intermediate mobility) and treatment four (high mobility), while the theory predicts a negative effect. As a result, an increase in the mobility level from moderate to high reduces inequality, again in contrast to the theory. We make two other observations about the magnitude of the effects: in all treatments, the observed tax rates are lower than the theoretical equilibrium; and the interactive effects of tax persistence and income mobility are larger in magnitude than the theory predicts.

The rest of the paper is organized as follows. Section 1.1 reviews the related literature. Section 2 presents the model. Section 3 derives the main theoretical results. Sections 4 and 5 describe the design and procedures of the experiment. Section 6 analyzes the results of the experiment. Section 7 offers some concluding remarks.

\subsection{Related Literature}

In the theoretical literature on social mobility and redistributive taxes, Benabou and Ok (2001) is most closely related to the present paper, but their model of social mobility is quite different from ours in a number of ways, including the mechanism driving the mobility effects. There are at least four differences. First, the distribution of income is exogenously specified in their model and is assumed to be unaffected by income taxation. In our model, individuals choose their labor supply optimally, conditional on the tax rate, so income is endogenous and taxes distort both the distribution and absolute levels of income, as in Meltzer and Richard (1981). Second, they consider only two possible redistributive tax regimes - one regime with a zero tax rate and a second regime in which all income is taxed and evenly redistributed to all individuals. While it may be useful for pedagogical purposes to consider these extreme cases, it is not realistic at all; and, moreover, neither of these two regimes is consistent with majority rule equilibrium in a model of voting over linear tax schemes. In our model, we characterize majority rule equilibrium in the space of linear tax schemes. Third, the POUM effect holds in their

model only for individuals with current income below the mean but whose future income is expected to be greater than the mean. In our model, such individuals do not exist: all individuals with an income below the mean today expect their income to be below the mean tomorrow. The mechanism driving POUM in our model is that individuals with an income below the mean today expect their income to be closer to the mean tomorrow, which marginally depresses their demand for redistribution, resulting in a lower ideal 
tax rate than they would prefer in a world without mobility. Fourth, Benabou and Ok require concavity of the social mobility transition function for their result. ${ }^{2}$ The mobility transition function in our model does not share this property: it is linear, not concave. That is, for all individuals, expected future income is a linear increasing function of today's current income. Our model also differs in more superficial ways, as well: we have a finite number of voters; a fixed distribution of productivities; an infinite horizon; and tax persistence that is modeled differently. As in their article, the present paper assumes risk neutrality, while risk aversion would tend to dampen the mobility and persistence effects.

Also related, but for a much different reason, is work by Piketty (1995), which focuses on the evolution of voter expectations about their own future social mobility. In his model, these expectations diverge as a result of their different past mobility experiences. In our theoretical model, we assume that voters know precisely the social mobility stochastic process, and so, in principle, such theoretical learning effects do not play any role in our model. A surprising finding from our experiment, however, is that learning from past mobility experiences within the experiment has a significant effect on individual agents' revealed preferences for redistribution that appears to be consistent with Piketty's theory.

Two experimental papers investigate social mobility effects in the laboratory. Konrad and Morath (2013) use a 2x2 design with three voters, where the first dimension compares behavior based on whether subjects are matched either with computer robots playing equilibrium strategies or with other subjects. The second dimension investigates how the possibility of future mobility may affect voter preferences over redistribution. However, in contrast to our model and the POUM literature more generally, taxes are not persistent in their model. In each period, the assignment of voter types (wages) is randomly reshuffled and, group matchings are reassigned, and each group chooses a new tax rate via a random dictatorship mechanism. ${ }^{3}$ Thus, there is no theoretical basis for a social mobility effect in their design. One of our treatments corresponds to that non-persistent tax regime design, and, as reported below, we find no effect of social mobility on tax rates. Konrad and Morath find marginally significant negative effects of perceived social mobility on preferences for redistribution, which they attribute to status concerns. Similar results are obtained both for the computer robot sessions and sessions with human interaction.

\footnotetext{
${ }^{2}$ Loosely stated, this implies that tomorrow's proportion of voters with incomes below the mean is less than the proportion of voters below the mean today. Such transition functions will depress today's mean income voter's demand for redistribution if the tax policy persists for both periods.

${ }^{3}$ In the random dictator mechanism, each voter simultaneously proposes a tax rate; the mechanism implements the highest or lowest tax rate with a $40 \%$ probability and chooses the median tax rate with a $60 \%$ probability.
} 
Checchi and Filippini (2004) report an experiment that tries to directly implement the Benabou and Ok (2001) model of social mobility - an individual choice experiment that involves no voting or group interaction. The authors also investigate the effect of socioeconomic, demographic, and attitudinal characteristics (including risk attitudes and social preferences) that were measured using a post-experiment survey. Neither the theoretical model underlying the Checchi and Filippini experiment nor the experimental design and methods are directly comparable to those in the present paper.

\section{The Model}

In this section, we lay out the primitives of the model and characterize equilibrium tax rates and labor supply. The society consists of $n>1$ infinitely-lived agents. In each period, agents operate in a perfectly competitive and frictionless labor market. In the initial period, $k=0$, agents are endowed with productivities

$$
w^{0}=\left(w_{1}^{0}, \ldots, w_{i}^{0}, \ldots, w_{n}^{0}\right)
$$

where $w_{i}^{0}$ denotes the productivity of agent $i$ in period 0 . To represent mobility, we assume that after each period, there is a probability $\alpha$ that the productivities are randomly reshuffled. Thus, if the profile of productivities is $w^{k}$ in period $k$, then agent $i$ 's productivity in period $k+1$ is $w_{i}^{k+1}=w_{i}^{k}$ with probability $(1-\alpha)$ and is equal to $w_{i}^{k+1}=w_{j}$ with probability $\frac{\alpha}{n}$ for each $j=1, \ldots, n$. Thus, the transition function is $w_{i}^{k+1}=w_{i}^{k}$ with probability $\left(1-\alpha+\frac{\alpha}{n}\right)$ and $w_{i}^{k+1}=w_{j}$ with probability $\frac{\alpha}{n}$ for each $w_{j} \neq w_{i}^{k}$.

Productivity plays an important role in determining agents' labor market behavior and incomes. In the labor market, which operates in each period, each agent chooses how much labor to supply. In a given period $k$, an agent $i$ with productivity $w_{i}^{k}$ that supplies $x_{i}^{k}$ units of labor earns pre-tax income $y_{i}^{k}=w_{i}^{k} \cdot x_{i}^{k}$ and bears an effort cost of $\frac{1}{2}\left(x_{i}^{k}\right)^{2}$, which represents the tradeoff between labor and leisure. Income and costs are measured in units of consumption. In addition, each agent pays a fraction $t^{k}$ of earned income in taxes. Below, we will describe in detail how tax rates are determined. Taxes are linear and are used solely for redistributive purposes: tax revenues are redistributed in equal shares among all agents in the society. Therefore, the payoff $u_{i}^{k}$ of agent $i$ in period $k$ consists of three parts: after-tax disposable income, cost of labor, and an equal share of collected taxes, with the last part depending on the labor decisions of other agents: 


$$
u_{i}^{k}\left(w_{i}^{k}, x_{i}^{k}, t^{k}\right)=\left(1-t^{k}\right) \cdot w_{i}^{k} \cdot x_{i}^{k}-\frac{1}{2}\left(x_{i}^{k}\right)^{2}+\frac{1}{n} \sum_{j=1}^{n} t \cdot w_{j}^{k} \cdot x_{j}^{k}
$$

All individuals discount future utility with a constant discount factor $\delta$; that is, the overall utility of agent $i$ is

$$
U_{i}=\sum_{k=0}^{\infty} \delta^{k} u_{i}^{k}
$$

Tax Regime. Society as a whole uses a democratic process to select a tax rate. That is, the tax rates are determined by majority rule equilibrium, which is based on rational expectations about how aggregate labor supply responds to changes in the income tax rates. In each period, agents choose their labor supply after observing their current-period productivity and the tax rate, to maximize (1). Tax persistence depends on a persistence parameter, $p$. Specifically, $p$ is the probability that the period $t$ tax rate persists in period $t+1$. With probability $1-p$, there is a new vote over the tax rate in period $t+1$, which will then persist until there is a new vote. Voting over taxes happens after agents learn their current-period productivities. In our model, the distribution of productivity types does not change over time (no aggregate uncertainty), so even when agents re-vote, the equilibrium tax rate will remain unchanged. However, this re-voting possibility still has an equilibrium effect purely through mobility, and, of course, it will also affect the value functions and the ideal tax rates of all voters. ${ }^{4}$

We assume that in the absence of taxation, the median income is lower than the average income - i.e., $\left(w_{m}^{k}\right)^{2}<\frac{1}{n} Z$, where $Z \equiv \sum_{i=1}^{n}\left(w_{i}^{k}\right)^{2}$ denotes per period aggregate income of the economy in every period $k$ if the tax rate is zero. This condition guarantees that in the static one-period model, the majority equilibrium is characterized by a positive amount of redistribution. If this condition does not hold, then the equilibrium tax rate equals 0 and mobility has no effect.

\subsection{Equilibrium Tax Rates}

In this section, we characterize agents' equilibrium behavior in both the labor market and the voting game. We assume that agents hold rational expectations regarding the

\footnotetext{
${ }^{4}$ Note that the mobility process specified above is completely governed by the parameters of the game $\left(\alpha,\left\{w_{i}\right\}_{i=1}^{n}\right)$ and is unrelated to agents' performance in the labor market in the preceding periods. We deliberately abstract away from additional forces that affect agents' behavior in a world where the prospect of upward mobility might depend positively on labor market performance. This allows us to isolate the effect of expectations of future mobility on preferences for redistribution, which is the main focus of this paper.
} 
aggregate labor supply response to changes in the tax rates in each period of the game and correctly anticipate the probabilities of upward and downward mobility and the persistence of the tax regime. Given that, in our model, the distribution of productivity types and the parameters that govern the likelihood of mobility and re-voting on tax policy do not change over time, agents' optimal behavior is time-independent. Thus, to ease the exposition, we suppress the superscript $k$, which denotes the period of the game. We present here the main intuition of the results and refer the reader to the Appendix for complete proofs.

Lemma 1. For a given a tax rate $t$, an agent with productivity $w_{i}$ supplies $x_{i}^{*}$ units of labor, where $x_{i}^{*}\left(w_{i}, t\right)=\left(1-t+\frac{t}{n}\right) w_{i}$.

The optimal labor supply of an agent depends only on the current tax rate and current economic status (productivity) and is independent of the labor supply decision of other agents, the prospects of upward mobility, and the persistence of taxes. This follows from the structure of the game, according to which agents can adjust their labor supply in every period, after experiencing mobility and/or changes in tax policy.

Next, we characterize preferences for redistribution for each productivity level, assuming that all agents choose their labor supply optimally, as characterized in Lemma 1. Consider agent $i$, who is currently endowed with productivity $w_{i}$. Her preferences over tax rates in the current period depend not only on her current productivity, but also on her prospects for future productivity, the persistence of the tax rate, and the future tax rate if the current tax rate expires. Because of the stationarity of the problem, with the distribution of agent types constant over time, the tax rate in the event of a tax regime change will always be $t^{*}(p)$, which is derived from simultaneously solving the dynamic program for all $n$ agent types. Each agent type, $w_{i}$, will have a long-run value associated with the current tax rate, denoted by $V_{i}\left(w_{i}, t\right)$. This generates a system of $n$ equations of the following form:

$$
\begin{aligned}
V_{i}\left(w_{i}, t\right) & =u_{i}^{*}\left(w_{i}, t\right)+\delta p\left[(1-\alpha) V_{i}\left(w_{i}, t\right)+\frac{\alpha}{n} \sum_{j=1}^{n} V_{j}\left(w_{j}, t\right)\right] \\
& +\delta(1-p)\left[(1-\alpha) V_{i}\left(w_{i}, t^{*}(p)\right)+\frac{\alpha}{n} \sum_{j=1}^{n} V_{j}\left(w_{j}, t^{*}(p)\right)\right] \quad \text { for } i=1, \ldots, n,
\end{aligned}
$$

where $u_{i}^{*}\left(w_{i}, t\right)$ is the optimal current period utility of an agent with productivity $w_{i}$ if 
the current tax rate is $t$. Using Lemma 1, we derive:

$$
u_{i}^{*}\left(w_{i}, t\right)=\frac{w_{i}^{2}}{2} \cdot\left((1-t)^{2}-\frac{t^{2}}{n^{2}}\right)+Z \cdot \frac{t}{n}\left(1-t+\frac{t}{n}\right),
$$

where $Z=\sum_{j=1}^{n} w_{j}^{2}$ represents the aggregate income of the economy if the tax rate is zero, and all workers choose labor optimally.

We solve the system of equations to obtain $\left\{V_{i}\left(w_{i}, t\right)\right\}_{i=1, \ldots, n}$. Ideal tax rates are then obtained for each agent type by the first-order condition with respect to $t$, and verifying second-order conditions (see Appendix).

Proposition 1. The ideal tax rate of agent $i$ with productivity $w_{i}$ is

$$
t_{i}^{*}\left(w_{i}\right)=\left[\begin{array}{ll}
\frac{n^{2}}{n^{2}-1} \cdot \frac{\frac{Z}{n}-\left(w_{i}\right)^{2}}{\frac{Z}{n+1}\left(2+\frac{\alpha \delta p}{1-\delta p} \cdot \frac{n-1}{n}\right)-\left(w_{i}\right)^{2}} & \text { if }\left(w_{i}\right)^{2}<\frac{Z}{n} \\
0 & \text { otherwise. }
\end{array}\right.
$$

When agents are completely impatient, $\delta=0$, or there is no mobility, $\alpha=0$, or taxes are non-persistent, $p=0$, the model reduces to the one-period model analyzed in Agranov and Palfrey (2015). At the other extreme, if agents are perfectly patient - i.e., $\delta \rightarrow 1$ - and tax rates are fully persistent - i.e., $p=1$ - then for all $\alpha>0$, we obtain that all agents, including those with the lowest current productivity, prefer no taxation and no redistribution since the expectation of future mobility outweighs the benefits of redistribution today, regardless of their current economic status: all they care about is their long-run average after-tax income, which is maximized at $t=0$. In intermediate cases, $\delta \in(0,1)$ and $p \in(0,1)$, agents with relatively low current productivity demand positive taxes, while those with relatively high productivities prefer zero taxation since their contribution to total collected taxes exceeds the tax refund that they would receive from redistribution. We show that each voter's indirect preferences over tax rates are singlepeaked, so the equilibrium tax rate depends on the preferences of the median-productivity agent: if $\left(w_{m}\right)^{2}<\frac{Z}{n}$, the society will choose a positive amount of redistribution that is equal to the ideal tax rate of the median agent - i.e., $t_{m}^{*}$; otherwise, the society will end up with no redistribution at all. ${ }^{5}$

Next, we show how equilibrium tax rates change in response to an increase in tax persistence parameter $p$ and economic mobility $\alpha$.

Corollary 1. Higher tax persistence leads to (weakly) lower equilibrium taxes.

\footnotetext{
${ }^{5}$ Notice that the interior equilibrium tax rates depend only on the product $\delta \cdot p$.
} 
Intuitively, all else equal, the longer the current tax regime lasts (the higher the $p$ ), the more likely currently low-productivity agents are to transition upwards and improve their economic status, in which case they would enjoy lower tax rates.

Corollary 2. Higher mobility leads to (weakly) lower equilibrium taxes.

Agents with relatively low productivity today have a greater chance of upward mobility in the future when reshuffling probability $\alpha$ increases, all else equal. Observe that there is also a counteracting effect by the higher types' prospect of downward mobility, which one might think would put upward pressure on the equilibrium tax rate. However, there is no such effect in equilibrium because the median voter's income is always below the average income, given our assumption of no aggregate uncertainty.

\subsection{Inequality}

How do tax persistence and economic mobility affect the level of inequality in the society? To measure inequality, we consider the dispersion of long-run incomes of agents. Specifically, the discounted net present value of agent $i$ with productivity $w_{i}$ in period 0 in equilibrium, in which the tax rate is $t^{*}$, can be written as

$$
V_{i}\left(w_{i}, t^{*}\right)=\frac{u_{i}^{*}\left(w_{i}, t^{*}\right)}{1-\delta(1-\alpha)}+\frac{\alpha \delta \cdot \bar{u}^{*}\left(t^{*}\right)}{(1-\delta)(1-\delta(1-\alpha)}
$$

where

$$
\bar{u}^{*}\left(t^{*}\right)=\frac{1}{n} \sum_{j=1}^{n} u_{j}^{*}\left(w_{j}, t^{*}\right)
$$

is per-period utility in equilibrium averaged across agents, and $u_{i}^{*}\left(w_{i}, t^{*}\right)$ is utility of agent $i$ with productivity $w_{i}$ in equilibrium, which is given by equation (9) evaluated at $t^{*}$. Thus, inequality in the society can be measured by the variance of long-run incomes - i.e.,

$$
\operatorname{var}\left(V_{i}\left(w_{i}, t^{*}\right)\right)=\frac{1}{n} \sum_{j=1}^{n}\left(V_{j}\left(w_{j}, t^{*}\right)-\bar{V}\left(t^{*}\right)\right)^{2}
$$

where

$$
\bar{V}\left(t^{*}\right)=\frac{1}{n} \sum_{j=1}^{n} V_{j}\left(w_{j}, t^{*}\right) .
$$

Proposition 2. An increase in tax persistence increases inequality in the society - i.e.,

$$
\frac{\partial \operatorname{var}\left(V_{i}\left(w_{i}, t^{*}\right)\right)}{\partial p}>0
$$


Higher tax persistence, $p \uparrow$, leads to a (weakly) lower equilibrium tax rate (Corollary 1). This, in turn, increases efficiency since lower taxes reduce distortions in the labor market, but also increase long-run inequality between agents. While higher stickiness of the tax regime unambiguously increases the dispersion of agents' incomes, the effect of income mobility is more complicated, as described in Proposition 3.

Proposition 3. For $Z>\bar{Z}\left(n, w_{m}\right)$ and $\delta<\bar{\delta}(\alpha, Z, n)$, there exists a unique $\bar{p}$ such that

$$
\begin{aligned}
& \frac{\partial \operatorname{var}\left(V_{i}\left(w_{i}, t\right)\right)}{\partial \alpha}<0 \text { for } p \in(0, \bar{p}) \\
& \frac{\partial \operatorname{var}\left(V_{i}\left(w_{i}, t\right)\right)}{\partial \alpha}>0 \text { for } p \in(\bar{p}, 1) .
\end{aligned}
$$

Otherwise, for all $p \in(0,1)$, we obtain $\frac{\partial \operatorname{var}\left(V_{i}\left(w_{i}, t\right)\right)}{\partial \alpha}<0$.

Intuitively, an increase in mobility parameter $\alpha$ has two main effects that work in opposite directions. First, higher mobility mechanically reduces inequality, as agents move up and down the income ladder more often. Second, higher mobility reduces equilibrium tax rates, which increases income inequality. When discount factor $\delta$ is high enough, the first effect naturally dominates the second one. The situation is more complicated when the discount factor is not too high - i.e., $\delta<\bar{\delta}\left(Z, w_{m}, n, \alpha\right)$. In this case, the magnitude of the two effects depends on the tax persistence. If tax rates are revised frequently - i.e., $p$ is low - then mobility reduces inequality since inequality is increasing in tax persistence. However, if the tax regime is sticky enough - i.e., $p$ is high - then, contrary to common wisdom, the long-run inequality increases with income mobility.

\section{Experimental Design}

\subsection{Parameterization}

The experiment we conducted uses a two-period environment in lieu of implementing an infinite-horizon environment with a random stopping rule. As we show below, this simplified two-period version of the model captures the most relevant features and comparative static predictions of the general infinite-horizon model. Each experimental treatment is characterized by the combination of tax persistence $p$ and mobility parameter $\alpha$. We used two extreme values of persistence, $p=0$ and $p=1$, and three values of mobility, $\alpha=0$, $\alpha=0.6$, and $\alpha=1$. Overall, we ran four different treatments with the following combinations of $(p, \alpha):(0,0),(0,0.6),(1,0.6)$ and $(1,1)$. In all treatments, we used groups of 
five agents, $n=5$, and the following vector of productivities:

$$
\left(w_{1}, w_{2}, w_{3}, w_{4}, w_{5}\right)=(5,5,5,10,10)
$$

In other words, there were two types of agents: those with low productivity (poor, denoted $w_{l}$ ) and those with high productivity (rich, denoted $w_{h}$ ). Since the majority is poor, the assumption $w_{m}^{2}<\frac{Z}{n}$ is satisfied. The overall payoff of agents in the two-period model is given by the sum of agents' payoffs in two periods, where the per-period payoff of agent $i$ is given by equation (9) evaluated at equilibrium tax rate $t^{*}$.

The equilibrium tax rate, $t_{(p, \alpha)}^{*}$, is determined by the ideal tax rate of the poor minority and depends on the combination of tax persistence and mobility parameters. When taxes are not persistent, the equilibrium tax rate is independent of $\alpha$ and is given by equation (5) with $p=0$ substituted in:

$$
t_{(0, \alpha)}^{*}=\frac{n^{2}}{n^{2}-1} \cdot \frac{\frac{Z}{n}-\left(w_{l}\right)^{2}}{\frac{2 Z}{n+1}-\left(w_{l}\right)^{2}} .
$$

When the tax rate chosen in period 1 persists in period 2 - i.e., $p=1$ - the equilibrium tax rate is given by:

$$
t_{(1, \alpha)}^{*}=\frac{n^{2}}{n^{2}-1} \cdot \frac{\frac{Z}{n}-\left[\chi(\alpha) \cdot\left(w_{l}\right)^{2}+(1-\chi(\alpha))\left(w_{h}\right)^{2}\right]}{\frac{2 Z}{n+1}-\left[\chi(\alpha) \cdot\left(w_{l}\right)^{2}+(1-\chi(\alpha))\left(w_{h}\right)^{2}\right]},
$$

where $\chi(\alpha)=1-\frac{\alpha(n-m)}{2 n}$ represents the relative frequency with which a period 1 poor agent remains poor in period 2. For the chosen parameters, the ideal level of redistribution for the rich minority is zero for all considered constellations of tax persistence and income mobility.

The overall incomes of poor and rich agents in the two-period model are given by

$$
\begin{gathered}
V_{i}\left(w_{l}, t_{(p, \alpha)}^{*}\right)=\left(2-\frac{2 \alpha}{5}\right) \cdot u^{*}\left(w_{l}, t_{(p, \alpha)}^{*}\right)+\frac{2 \alpha}{5} \cdot u^{*}\left(w_{h}, t_{(p, \alpha)}^{*}\right) \\
V_{i}\left(w_{h}, t_{(p, \alpha)}^{*}\right)=\frac{3 \alpha}{5} \cdot u^{*}\left(w_{l}, t_{(p, \alpha)}^{*}\right)+\left(2-\frac{3 \alpha}{5}\right) \cdot u^{*}\left(w_{h}, t_{(p, \alpha)}^{*}\right) .
\end{gathered}
$$

These expressions are used to assess the level of inequality in the society, as measured by the variance of the long-run incomes from the period 1 perspective, after period 1's productivities are assigned. Table 1 summarizes the theoretically predicted equilibrium tax rates and levels of inequality in our four experimental treatments. 
Table 1: Parameters and Experimental Design

\begin{tabular}{c|clccccc}
\hline \hline Treatment & Tax Persistence & Mobility & $t_{(p, \alpha)}^{*}$ & $\operatorname{var}\left(V_{i}\right)$ & \# sessions & \# groups & \# subjects \\
\hline NM & $p=0$ & $\alpha=0$ & 0.47 & 99.93 & 3 & 12 & 60 \\
M1 & $p=0$ & $\alpha=0.6$ & 0.47 & 69.95 & 4 & 17 & 85 \\
M2 & $p=1$ & $\alpha=0.6$ & 0.38 & 135.47 & 3 & 16 & 80 \\
M3 & $p=1$ & $\alpha=1.0$ & 0.30 & 159.69 & 3 & 17 & 85 \\
\hline \hline
\end{tabular}

The two versions of the model, the infinite-horizon model discussed in Section 2 and the simplified two-period model described in this section, share the main comparative static predictions with respect to mobility and tax persistence parameters, which are the focus of this project. We formulate the following hypotheses based on the theoretical model:

Hypothesis 1: When taxes are not persistent, prospects of income mobility have no effect on equilibrium tax rates - i.e., $t_{(0,0)}^{*}=t_{(0,0.6)}^{*}$.

Hypothesis 2: For a fixed mobility $\alpha$, higher tax persistence leads to lower equilibrium tax rates - i.e., $t_{(0,0.6)}^{*}>t_{(1,0.6)}^{*}$.

Hypothesis 3: For a fixed level and positive level of tax persistence $p$, an increase in mobility parameter $\alpha$ leads to lower equilibrium tax rates - i.e., $t_{(1,0.6)}^{*}>t_{(1,1)}^{*}$.

Hypothesis 4: For a fixed mobility $\alpha$, an increase in the persistence of taxes leads to higher inequality - i.e., $\operatorname{var}\left(V_{i}\left(w_{i}, t_{(0,0.6)}^{*}\right)\right)<\operatorname{var}\left(V_{i}\left(w_{i}, t_{(1,0.6)}^{*}\right)\right)$.

Hypothesis 5: The effect of an increase in mobility $\alpha$ on overall inequality depends on the tax persistence. When taxes are not persistent, higher mobility leads to lower inequality - i.e., $\operatorname{var}\left(V_{i}\left(w_{i}, t_{(0,0)}^{*}\right)\right)>\operatorname{var}\left(V_{i}\left(w_{i}, t_{(0,0.6)}^{*}\right)\right)$. The effect is the opposite when taxes are persistent: higher mobility leads to higher inequality - i.e., $\operatorname{var}\left(V_{i}\left(w_{i}, t_{(1,0.6)}^{*}\right)\right)<$ $\operatorname{var}\left(V_{i}\left(w_{i}, t_{(1,1)}^{*}\right)\right)$.

\subsection{Experimental Protocol}

All experimental sessions were conducted at the ESSL (Experimental Social Science Laboratory) at University of California, Irvine. Subjects were recruited from the general undergraduate population, from all majors. Experiments were conducted using Multistage software, which was developed from the open source Multistage package. ${ }^{6}$ We conducted

\footnotetext{
${ }^{6}$ Multistage package is available for download at at http://software.ssel.caltech.edu/.
} 
13 sessions, using a total of 310 subjects. No subject participated in more than one session. The experiments lasted, on average, one and a half hours, and subjects' average earnings were $\$ 28$, including the $\$ 7$ show-up fee. ${ }^{7}$

For all four treatments, an experimental session consisted of three parts. In Part I, we elicited the subjects' risk attitudes using the investment task of Gneezy and Potters (1997). ${ }^{8}$ In this task, subjects are given 100 points, which are worth $\$ 2$, and they allocate these points between a safe investment, which returns one point for each point invested, and a risky investment, which returns 2.2 points for each point invested with probability $50 \%$ and produces no returns for the investment with probability 50\%. Any amount earned from this task was added to the overall earnings in the session.

For the next two parts of the experiment (Parts II and III), subjects were divided into groups of five subjects: three were assigned low productivity of 5 , and two were assigned high productivity of 10. During the entire experiment, subjects interacted only with other subjects assigned to their own group, so each group of five people represents an independent observation for the statistical analysis, hereafter.

Part II consisted of ten periods. In this part of the experiment, subjects gained experience with the labor market. At the beginning of each period, agents were informed of the tax rate for that period. Then they chose how much labor to supply without knowing what other subjects in their group chose. Labor supply decisions could to be any number between 0 and 15 with up to two decimal places. ${ }^{9}$ After all five agents had made their choice, subjects received feedback that specified the labor supply of each agent in their group, and an agent's own payoff was displayed on the screen, broken down into three parts: after-tax income, the quadratic cost of labor, and their tax rebate (equal share of collected taxes). When the period ended, the group moved on to the next period, which was identical to the previous one, except for the tax rate imposed at the beginning of the period. In this training part of the session, subjects went through different possible tax rates, in the following order: $0.50,0.15,0.70,0.62,0.35,0.05,0.27,0.75,0.90$, and 0.20 .

Part III was the main part of the experiment. This was also the only part that differed across the four treatments and consisted of the ten matches, with each match being the two-period game described in Section 3.1. In each of the ten matches, the productivity of

\footnotetext{
${ }^{7}$ The complete instructions for one of our treatments are presented in the Appendix.

${ }^{8}$ This method is among the more common methods for eliciting risk attitudes of subjects in laboratory experiments (see survey of Charness, Gneezy and Imas (2013)).

${ }^{9}$ We used neutral terminology in the experiment and avoided references to work, effort, productivity or other terms associated with labor market or relative income. Instead, individual labor supply decisions were called investment levels and productivities were called values.
} 
subjects in period 1 was fixed and was the same as the productivity they were assigned at the beginning of Part II. Second-period productivities were reassigned depending on the value of $\alpha$ in each treatment: in the NM treatment, there was no income mobility - i.e., $\alpha_{N M}=0$; in Treatments M1 and M2, the mobility parameter was $\alpha_{M 1}=\alpha_{M 2}=0.6$; and in M3, the mobility parameter was $\alpha_{M 3}=1$. In treatments with $\alpha>0$, when subjects were reassigned productivities in period 2, exactly three out of five subjects in a group were randomly chosen to receive low productivity of 5 , and the two remaining subjects received high productivity of 10 .

In the NM and M1 sessions, at the beginning of each period of each match, subjects observed their productivity for the current period and were asked to submit a proposal for the tax rate in the current period. The median proposal (third-lowest tax rate) was announced to all subjects and implemented for that period. We chose this mechanism because every member has a dominant strategy to propose her ideal tax rate. ${ }^{10}$ After the tax rate for the current period was determined, subjects chose their labor supply as in Part II of the experiment. At the end of the period, subjects got to observe their payoff for this period along with all labor supply decisions and tax proposals of the other subjects in their group. In the NM treatment, period 2 productivities were the same as in period 1 , and subjects were informed in advance that this would be the case. In Treatment M1, depending on the realization of $\alpha$, period 2 productivities were either the same or different. Note that the subjects knew that period 2 tax rates would be determined after they learned their period 2 productivities. This two-period game was repeated ten times (ten matches).

In the M2 and M3 sessions, subjects proposed tax rates only once, in period 1. The tax proposals were elicited after they were informed of their own period 1 productivities, but before they knew whether or not their productivity would change in period 2 . The instructions provided subjects with explicit calculations of their chances of experiencing mobility in period 2. The median proposal was then announced to all subjects and implemented in both periods of that match. The remaining details of Treatments M2 and M3 were exactly the same as those of NM and M1. That is, after the tax rate in period 1 was determined, subjects chose their labor supply for period 1. After that, subjects learned their payoff for period 1, as well as the period 1 labor supply decisions and tax proposals made by other members of their group. Then, subjects proceeded to period 2 , in which they each first learned the (possibly different) period 2 productivities of all group members, including their own, chose labor supply given the tax rate previously

\footnotetext{
${ }^{10}$ Agranov and Palfrey (2015) also used this voting method.
} 
determined in period 1, and observed the period 2 payoffs and choices made by other subjects in their group. This two-period game was repeated ten times (ten matches).

To help subjects calculate hypothetical earnings from different labor supply and tax choices, we provided them with a built-in calculator that appeared on their monitors. Subjects could use the calculator before submitting their tax proposals and before making their labor decisions. For labor supply decisions, to use the calculator, subjects had to make three choices: the productivity for which they wanted to observe the hypothetical payoff; a labor supply decision for the chosen productivity level; and a guess of the total taxes collected from the other members in the group. For proposing tax rates, subjects also had to enter a fourth parameter: the tax rate for which the hypothetical period earnings would be computed. After the subjects entered all of their information, the calculator computed the payoff of a subject with chosen productivity in this hypothetical scenario. Subjects could use this calculator as many times as they wanted to. ${ }^{11}$

The number of sessions conducted and the number of participants in each treatment are summarized in Table $1 .^{12}$

\section{Results}

We present the results of our experiments using the theoretical framework described above as our basis. We start by comparing implemented taxes, subjects' labor supply decisions and overall inequality levels across our experimental treatments. We test the five hypotheses summarized in Section 3.1 and document any quantitative and qualitative differences between observed and predicted outcomes (Section 4.1). We then investigate several mechanisms that can account for these differences (Section 4.2). This part of the analysis focuses on identifying the main determinants of preferences for redistribution in the presence of income mobility.

Most of the statistical analysis that follows focuses on the last five matches in each treatment, which we refer to as the experienced matches. This is standard approach in the literature that reduces noise in the data due to learning in the first iterations of the game. To compare average outcomes between two groups (whether two periods of the same treatment or two different treatments), we use random effects TOBIT regressions.

\footnotetext{
${ }^{11}$ See the Appendix for sample screenshots.

${ }^{12}$ Two groups of five subjects in the NM treatment were interrupted during the session due to computer crashes. However, since subjects interacted only within their own group and were never rematched with other subjects, these difficulties did not affect the functioning of other subjects in these sessions. We exclude these two groups from the analysis.
} 
Specifically, we regress the outcome of interest - i.e., implemented tax rates, labor supply decisions or income dispersion - on a dummy variable that indicates one of two considered groups, with standard errors clustered at the group level, to account for interdependencies of observations that come from the same group. We say that the difference between outcomes in the two groups is statistically significant if the estimated coefficient on the dummy variable is different from zero at the standard $5 \%$ significance level, and we report the $p$-values associated with it. To compare inequality levels between two treatments, as measured by variance of agents' total incomes, we use a two-sample variance ratio test and report $p$-values associated with the statistics. Finally, to compare observed outcomes with those predicted by theory, we use random effects GLS regressions, in which we regress the variable of interest on a constant term alone, while clustering observations by groups. We report the p-value of a test where the null hypothesis is that the estimate equals the theoretically predicted value.

\subsection{Treatment Effects}

\subsubsection{Implemented Taxes}

Figure 1 displays the time path of the average implemented taxes in each treatment, while Table 2 presents the average taxes observed in the experienced matches.

Figure 1: Implemented Taxes (averaged across groups in a match)

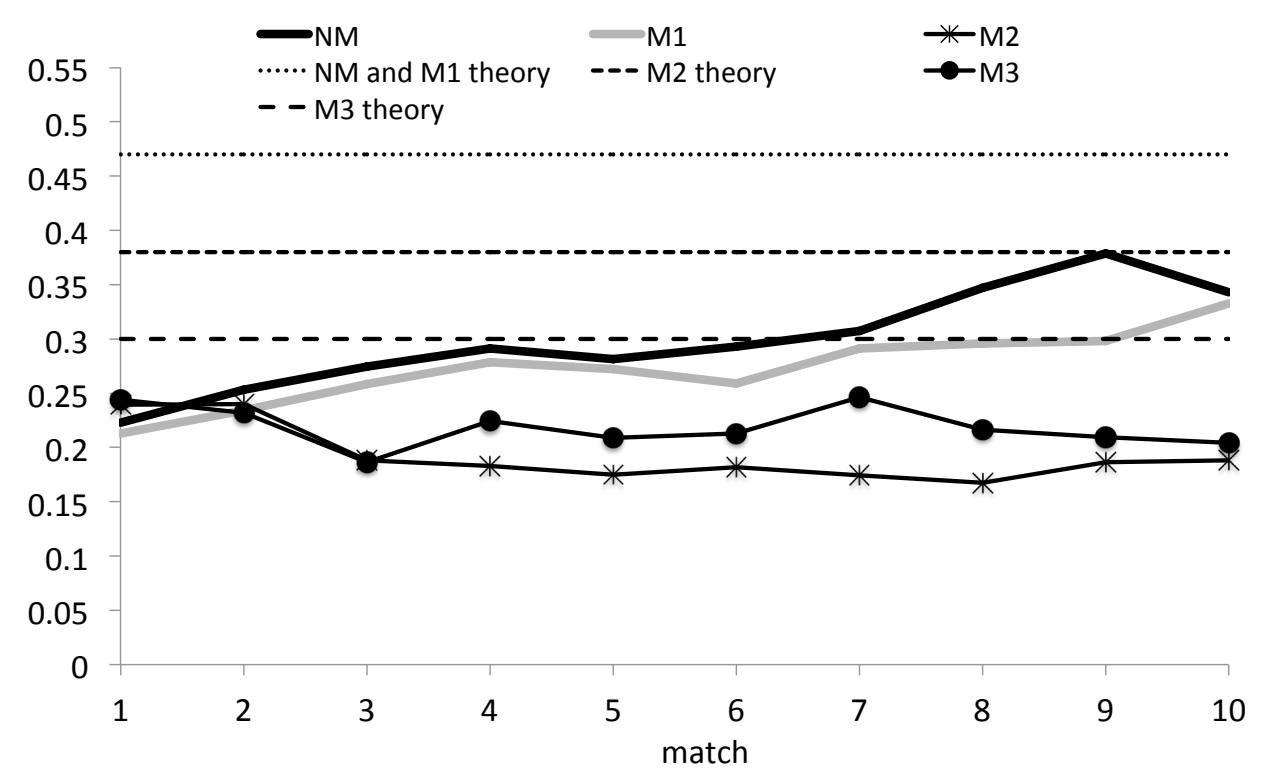

Notes: In the NM and M1 treatments, we pool the data from the first and second periods. 
Table 2: Average Implemented Tax Rates in Experienced Matches

\begin{tabular}{l|c|c|c|c}
\hline & NM $\left(t^{*}=0.47\right)$ & M1 $\left(t^{*}=0.47\right)$ & M2 $\left(t^{*}=0.38\right)$ & M3 $\left(t^{*}=0.30\right)$ \\
mean (se) & mean (se) & mean (se) & mean (se) \\
\hline Period 1 & $0.34(0.04)$ & $0.30(0.04)$ & $0.18(0.04)$ & $0.22(0.04)$ \\
Period 2 & $0.33(0.04)$ & $0.29(0.03)$ & $0.18(0.04)$ & $0.22(0.04)$ \\
\hline Pooled across Periods & $0.33(0.04)$ & $0.30(0.03)$ & $0.18(0.04)$ & $0.22(0.04)$ \\
\hline
\end{tabular}

Notes: $t^{*}$ depicts the theoretically predicted equilibrium tax rate in each treatment. Robust standard errors are in parentheses, clustered by group.

When taxes are not persistent and agents make decisions about the tax rate after they learn their productivities in each period of the game, the presence of income mobility is predicted to have no effect on the amount of redistribution (Hypothesis 1). To test this hypothesis, we compare implemented taxes in the M1 and NM treatments. As is evident from Table 2, this hypothesis is borne out in our data: pooling the data from both periods, we observe no significant difference between tax rates in the NM and M1 treatments $(p=0.454) .{ }^{13}$ Moreover, given that our setup features no aggregate uncertainty, tax rates in both periods of the NM and M1 treatments are predicted to be the same. Regression analysis confirms this for both the NM treatment $(p=0.332)$ and the M1 treatment $(p=0.619)$.

For a fixed level of income mobility, higher tax persistence leads to a lower amount of redistribution, as the pivotal voter expects to climb the income ladder with some positive probability and is willing to trade off some current income in anticipation of this potential move (Hypothesis 2). To test this hypothesis, we compare tax rates in the M1 and M2 treatments, which both feature $\alpha=0.6$ and differ only in their tax persistence parameter $p$. Hypothesis 2 is borne our in our data: tax rates in the M2 treatment are significantly lower than those in both periods of the M1 treatment $(p=0.015)$.

Finally, for a fixed and positive level of tax persistence, higher income mobility is predicted to lower equilibrium tax rates, as upward mobility is more likely for the pivotal voter (Hypothesis 3). Contrary to this hypothesis, we detect no significant difference between the average implemented taxes in the M2 and M3 treatments $(p=0.440)$. We do, however, observe a higher amount of redistribution in the NM and M1 treatments compared to the M3 treatment, which indicates that the combination of higher mobility and higher tax persistence has a significant effect on the level of redistribution $(p=0.024$

\footnotetext{
${ }^{13}$ We reach the same conclusion when we perform a regression analysis separately for each of the two periods of the game: $p=0.412$ and $p=0.521$ for comparison of the NM and M1 treatments in the first and second period, respectively.
} 
for the M3 versus the NM treatment and $p=0.094$ for the M3 versus the M1 treatment).

While most of the comparative static hypotheses of levels of redistribution across our treatments follow theoretical hypotheses, the levels are off. As is apparent in Figure 1 and Table 2, and is confirmed by regression analysis, for each treatment, we reject the null that the average implemented tax rate equals the theoretically predicted one $(p=0.001$ for NM, $p<0.001$ for M1, $p<0.001$ for M2, and $p=0.0205$ for M3). In all cases, the implemented tax rates are lower than predicted. We explore possible causes of these differences in Section 4.2.

\subsubsection{Labor Supply Decisions}

Table 3: Estimated Normalized Labor Supply Functions in Experienced Matches

\begin{tabular}{|c|c|c|c|c|}
\hline & \multicolumn{2}{|c|}{ NM } & \multicolumn{2}{|c|}{ M1 } \\
\hline & const (se) & slope (se) & const (se) & slope (se) \\
\hline Poor & $0.99(0.02)$ & $-0.76(0.04)$ & $1.01(0.02)$ & $-0.78(0.04)$ \\
\hline \multirow[t]{3}{*}{ Rich } & $0.98(0.03)$ & $-0.76(0.05)$ & $1.01(0.02)$ & $-0.84(0.04)$ \\
\hline & \multicolumn{2}{|c|}{ M2 } & \multicolumn{2}{|c|}{ M3 } \\
\hline & const (se) & slope (se) & const (se) & slope (se) \\
\hline Poor & $1.03(0.03)$ & $-0.81(0.10)$ & $0.98(0.02)$ & $-0.74(0.05)$ \\
\hline Rich & $1.00(0.02)$ & $-0.80(0.08)$ & $0.98(0.21)$ & $-0.74(0.05)$ \\
\hline
\end{tabular}

Notes: Random effects TOBIT regressions of normalized labor supply decisions regressed on implemented tax rates and a constant, using data from both periods and clustering standard errors by the group. Normalized labor supply is labor supply divided by productivity. ${ }^{* *}$ indicates that theoretically predicted value of a coefficient falls outside of $95 \%$ confidence interval of estimated coefficients (we observe no such case).

Lemma 1 predicts no treatment effects on labor supply functions. Indeed, the optimal choice of labor depends exclusively on the level of redistribution and an agent's own productivity, both of which are known at the time agents make their labor choices. To check this hypothesis, we regress the normalized labor supply on the tax rate and a constant, where the normalized labor supply is labor supply divided by productivity. Theory predicts that the coefficient on the tax rate is -0.8 with a constant term equal to 1 , for both productivity types, independently of the treatment and the period of the game. Table 3 reports the estimated coefficients from random-effects TOBIT regressions using data from the experienced matches in each treatment and each productivity level separately, with standard errors clustered at the group level. ${ }^{14}$ As is evident from Table

\footnotetext{
${ }^{14}$ In the Appendix, we report similar regressions conducted separately for each period of the game using
} 
3 in all 16 cases, theoretically predicted values fall inside a 95\% confidence interval of the estimated coefficient. Thus, we conclude that labor supply decisions of both poor and rich agents in all four treatments are, in general, consistent with the theoretically predicted ones. In particular, we observe no systematic deviations in the labor market decisions that could indicate the presence of other-regarding preferences such as altruism or inequality aversion.

\subsubsection{Inequality}

In this section, we turn our attention to the overall level of inequality in the society, which, in theory, depends on the various parameters of the environment, including the persistence of the tax regime, the (endogenous) tax rate, and the degree of mobility, all of which interact in a non-trivial way, as discussed in Section 2.2. Following theoretical investigation, in this section, we measure the inequality in society by the dispersion (variance) of agents' total income over the course of both periods. ${ }^{15}$ In the Appendix, we show that the same conclusions would be reached if one were to use GINI coefficients to study inequality levels across our four experimental treatments. Table 4 presents observed and theoretical levels of total income dispersion across our experimental treatments.

Table 4: Inequality Levels Across Treatments in Experienced Matches

\begin{tabular}{|c|c|c|c|c|c|}
\hline & \multicolumn{2}{|c|}{ Theory } & \multicolumn{3}{|c|}{ Observed } \\
\hline & $\begin{array}{l}\text { theoretical } \\
\text { mobility freq }\end{array}$ & $\begin{array}{c}\text { empirical } \\
\text { mobility freq }\end{array}$ & mean & median & robust $\mathrm{SE}$ \\
\hline NM & 99.93 & 99.90 & 403.44 & 304.75 & 81.50 \\
\hline M1 & 69.95 & 70.54 & 305.90 & 165.93 & 60.53 \\
\hline M2 & 135.47 & 138.09 & 488.24 & 379.57 & 62.59 \\
\hline M3 & 159.69 & 164.39 & 357.24 & 235.43 & 58.79 \\
\hline
\end{tabular}

Notes: Variance of agents' total incomes is reported for each treatment separately. The total income is the sum of agents' utilities in both periods of the game, which consists of after-tax income, costs of labor and tax rebate. Theoretical values of variance are reported using theoretical mobility frequencies (column 1) and empirical realizations of mobility (column 2). Observed variance is computed using subjects' total incomes separately for each group in each of the last five matches of each treatment. The robust standard errors are obtained by clustering observations by individual groups.

all ten matches, as well as regressions in which we consider experienced matches and cluster standard errors by subjects. These estimations produce results very similar to the ones presented here and, therefore, are omitted from the main text for brevity.

${ }^{15}$ To be consistent with the theoretical analysis, our measure of total income of agents across two periods sums up agents' utility in both periods, which includes after-tax income, costs of labor and tax rebate. The alternative measure that nets out the quadratic cost of effort, which represents a labor-leisure trade-off, yields similar results and is omitted from the main text of the paper for brevity purposes. 
For a given level of mobility, an increase in persistence of taxes is predicted to increase inequality, as it lowers the equilibrium tax rates selected by the democratic process (Hypothesis 4). To test this hypothesis, we compare the inequality levels in M1 and M2, which hold the mobility parameter constant and vary the tax persistence parameter. This hypothesis is borne out in our data, as M2 features significantly higher inequality levels than M1 (Two-sample variance ratio test: $p<0.001$ ).

The effect of income mobility on inequality levels is more complex, as it depends on how persistent the tax regime is. Our parameterization captures two different scenarios: (1) higher income mobility reduces inequality when taxes are not persistent; and (2) higher income mobility increases inequality when taxes are persistent (Hypothesis 5). To test the first part of Hypothesis 5, we compare inequality levels in the NM and M1 treatments, both of which feature non-persistent tax regimes, but only M1 incorporates mobility. Our data confirm that inequality decreases when mobility is introduced; however, the effect is quite modest (One-sided variance ratio test: $p=0.0561$ ).

To test the second part of Hypothesis 5, we compare inequality levels in the M2 and M3 treatments, both of which feature persistent tax regimes, but M3 has higher mobility than M2. Contrary to the theory, we observe lower inequality in M3 than in M2 (Twosided variance ratio test: $p=0.002$ ). To reconcile this evidence with previously reported implemented tax rates, recall that an increase in income mobility affects inequality in two opposing ways: first, higher mobility mechanically reduces inequality, as agents' productivities are reshuffled more often; second, higher mobility leads to lower equilibrium tax rates, which increases inequality since society engages in less redistribution. However, as is evident from Figure 1, Table 2, and the analysis presented in Section 4.1.1, the tax rates in the M2 and M3 treatments are fairly similar. Therefore, the dominant effect between the two described above is the one that works in the direction of reducing inequality.

Finally, in all four treatments, the levels of observed inequality are much larger than those predicted by theory. There are two reasons for that. First, as we documented above, the average implemented tax rates are generally below the equilibrium rates. This by itself increases the inequality since lower levels of redistribution increase the dispersion of agents' incomes. Second, in all treatments, there are several group outliers that implement zero tax rates; these groups drive the levels of dispersion up in all treatments. 


\subsection{Understanding deviations from the theory}

There are several interesting features of the data in terms of both the dynamic evolution of tax rates across the ten matches and the tax-rate levels. In both periods and in all four treatments, the implemented tax rates are significantly below the theoretical rates. Even after subjects experienced the game for five matches, in both the NM and M1 treatments, the average implemented taxes were around 30\%, while the theoretical equilibrium tax rate is $47 \% .{ }^{16}$ While in both treatments, there is a clear upward trend in the direction of the equilibrium tax rate, it remains below $40 \%$ even in the last few matches. This effect of below-equilibrium taxes is even stronger in the two treatments with income mobility and persistent taxes (M2 and M3). There, we observe tax rates that are one half to two thirds of the equilibrium tax rates, and the time series of implemented taxes across matches does not show any upward trend, as was the case in NM and M1.

Note that our hypotheses for equilibrium tax rates were derived under the assumption of agents' risk neutrality. A natural question is: what happens if one allows for risk-averse preferences? It is easy to see that allowing for risk-averse preferences would change our hypotheses only in the treatments that feature persistent tax regimes. When the tax regime is non-persistent, agents' risk attitudes do not affect the equilibrium tax rates since taxes are adjusted in every period following any changes in agents' productivities. Furthermore, for treatments with persistent taxes (M2 and M3), the equilibrium tax rates with risk-averse agents are predicted to be higher than the equilibrium tax rates with risk-neutral agents. This is a direct implication of the concavity of the utility function of pivotal poor agents. Therefore, risk aversion cannot account for the deviations observed in our experiments.

What can account for the fact that observed tax rates are significantly below equilibrium tax rates in all of our treatments? Why do the learning patterns look very different between treatments with non-persistent and persistent taxes? This is the focus of the current section.

\subsubsection{Mechanical downward bias of implemented taxes}

Our first observation is that the current setup features a purely mechanical bias in the direction of lower-than-equilibrium taxes, and when one adjusts for this bias, the results

\footnotetext{
${ }^{16}$ This finding is surprising in light of past findings to the contrary documented in Agranov and Palfrey (2015), who study taxation and redistribution in a one-period setup similar to the one studied here, except that in their setup, societies consist of five different productivity levels, rather than the two levels (poor and rich) in our setup.
} 
indeed replicate the past findings of Agranov and Palfrey (2015). ${ }^{17}$ The mechanical bias works in the following way. Because the ideal tax rate of poor voters is $47 \%$ and the ideal tax rate of rich voters is $0 \%$, the pivotal voter is (theoretically) a poor voter. Although this is what is usually observed in the data, there is significant between-subject variation in the poor voters' proposals. Indeed, in all four treatments, in the vast majority of elections, the poor voter was the pivotal one. ${ }^{18}$ Thus, it is nearly always the case that the lowest proposed tax rate among the poor voters is implemented since the two rich voters usually propose very low taxes.

As a consequence of this heterogeneity, even if, on average, the taxes proposed by the poor voters are equal to the equilibrium tax rate, the implemented tax rate under the proposal mechanism will be biased downward. ${ }^{19}$

To check and see if it is this mechanical bias that causes the low taxes in NM and M1, Figure 2 displays the time series of the median tax rate proposed by the three poor voters in a group, averaged across groups. In both treatments without persistence of taxes (NM and M1), the average median proposed tax rate by poor voters starts below the equilibrium level but adjusts upward over time, reaching a level approximately equal to the equilibrium tax rate by the end of the experiment. ${ }^{20}$

Regardless of the tax regime and mobility parameters, correction for this mechanical bias has a big effect on observed taxes proposed by poor voters. While in all treatments, this de-biasing brings the level of the time series of tax rates towards the equilibrium tax rate, the evolution of proposed tax rates is different across treatments. In all treatments, proposals of poor voters in the first match concentrate around 35\%-40\% tax rates. However, as subjects gain experience with the game, the treatments separate out, with a noticeable increase in treatments with non-persistent taxes (NM and M1) and a decrease in treatments with persistent taxes (M2 and M3).

To evaluate the effect of the mechanical bias in a statistical sense, the first two columns in Table 5 depict tax proposals of poor voters in each treatment in the experienced matches and the corresponding theoretical predictions for such proposals. Statistical analysis re-

\footnotetext{
${ }^{17}$ Treatments NM and M1, which feature no tax persistence, can be viewed as robustness checks on early studies that investigate equilibrium taxation and redistribution in a one-period static setting.

${ }^{18}$ Specifically, in the last five matches, in $80 \%$ of elections in the NM treatment, the group's median proposal comes from one of the poor voters. The corresponding fractions in the remaining treatments are $69 \%, 82 \%$ and $87 \%$ for M1, M2 and M3, respectively.

${ }^{19}$ This was not an issue in the earlier Agranov and Palfrey (2015) study because the five voters' ideal tax rates were spread out, in contrast to the present design.

${ }^{20}$ This pattern of initially low tax rates followed by upward adjustment in the direction of equilibrium is exactly the same pattern that Agranov and Palfrey (2015) reported, using a different distribution of types and only one tax period.
} 
Figure 2: Tax Rate Proposed by Poor Voters (averages per match)

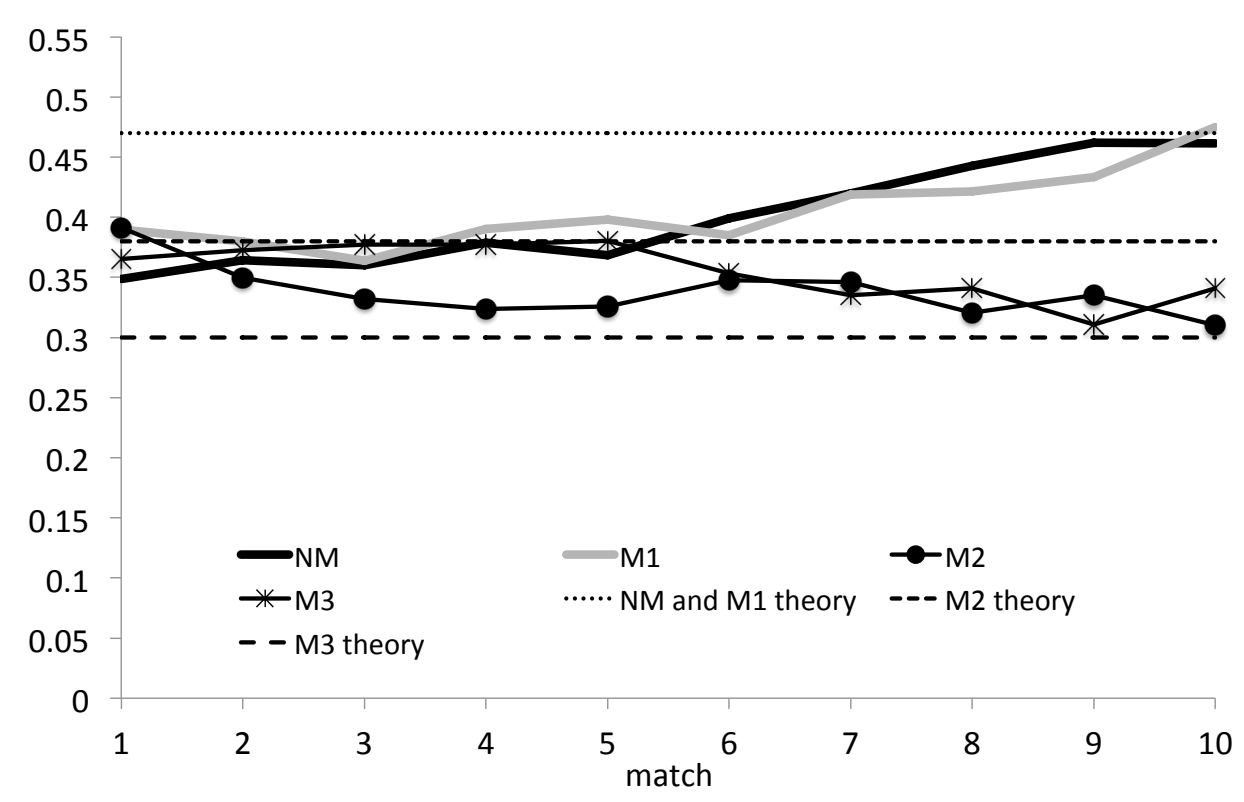

Notes: In the NM and M1 treatments, we pool the data from the first and the second periods.

veals that one cannot reject the null hypothesis that tax proposals of poor voters in the experienced matches are equal to the theoretically predicted ones in all four treatments: $p=0.4262$ in NM, $p=0.2308$ in M1, $p=0.3036$ in M2, and $p=0.4144$ in M3. In other words, we find that with the correction for the mechanical bias, the average tax rate proposed by poor voters converges to their ideal tax rate, as predicted by the theory.

Table 5: Average Proposed Tax Rates in Experienced Matches

\begin{tabular}{l|cc|cc}
\hline & \multicolumn{2}{|c|}{ Proposals by Poor } & \multicolumn{2}{c}{ Proposals by Rich } \\
& theory & mean (se) & theory & mean (se) \\
\hline NM & 0.47 & $0.44(0.04)$ & 0.00 & $0.11(0.03)$ \\
M1 & 0.47 & $0.43(0.04)$ & 0.00 & $0.16(0.03)$ \\
M2 & 0.38 & $0.33(0.05)$ & 0.00 & $0.07(0.02)$ \\
M3 & 0.30 & $0.34(0.04)$ & 0.00 & $0.10(0.03)$ \\
\hline
\end{tabular}

Notes: In the NM and M1 treatments, we pool the data from the first and the second periods.

\subsubsection{Experienced mobility}

Besides the mechanical effect described above, whereby heterogeneity alone can lead to a downward bias in taxes, we consider another factor that may affect subjects' preferences 
for redistribution in the presence of mobility and a persistent tax regime. This is a purely behavioral factor, which we refer to as the experienced mobility hypothesis. According to this hypothesis, some poor voters' beliefs about the likelihood of upward mobility may be affected by the relative frequency of mobility in the early matches of a session. This purely behavioral explanation is because the subjects were told at the start of the experiment the exact details of the match-independent stochastic mobility process used in the experiment. Thus, there would be no mathematical reason for subjects to update their beliefs about it in response to past observations. Nonetheless, one can imagine them doing so. This experienced mobility hypothesis resembles the inference problem of agents explored by Piketty (1995), according to which agents learn about the determinants of economic success and likelihood of mobility through personal and dynastic experimentation. Heterogeneity in long-run beliefs about the prospects of mobility in these models is a natural consequence of this learning process that involves costly effort. ${ }^{21}$

To test the experienced mobility hypothesis, in Table 6, we present the results of separate random effects TOBIT regressions for the M2 and M3 treatments, in which we regress tax rates proposed by poor voters on a measure of an individual voter's experience with mobility, controlling for her previous match proposal, the match number and her risk attitudes. For both M2 and M3, we use the voter's observed cumulative frequency (between 0 and 1) of experiencing upward mobility in previous matches. In addition, for M2, we include a separate variable that is the cumulative frequency with which their group experienced mobility in previous matches. ${ }^{22}$

Several interesting patterns emerge from the estimations presented in Table 6. First, poor voters respond to past mobility experience in their choices of the current tax proposals. Specifically, in both M2 and M3, poor voters propose lower taxes in response to experiencing upward mobility in previous matches. The effect is highly significant, substantial and of the same magnitude for both M2 and M3 treatments. In particular, if a subject were to experience mobility in half of the previous matches, this would, on average, increase her tax proposal by about seven percentage points compared to never having experienced upward mobility. Furthermore, in M2, the frequency with which a voter's group experiences mobility in past matches has a negative effect - significant and

\footnotetext{
${ }^{21}$ See also Ravallion and Lokshin (2000), as well as Corneo and Gruner (2002), who consider the perception of mobility experienced at the community level and argue that individuals form their expectations through the lens of observing what happens around them.

${ }^{22}$ In the M2 treatment, the fraction of times that the group would experience and observe mobility is 0.9. $\alpha=0.54$ because there is $10 \%$ chance that reshuffling productivities yields the exact same productivities for all five agents in a group. The second measure of experienced mobility is not included in the M3 regression because subjects were informed that reshuffling occurred in every match.
} 
Table 6: Effect of Experienced Mobility on Tax Proposals of the Poor

\begin{tabular}{l|cc}
\hline \hline & M2 & M3 \\
\hline Cumulative frequency of own mobility at $t-1$ & $-13.99^{* *}(0.02)$ & $-14.08^{* *}(0.01)$ \\
Cumulative frequency of observing mobility in $t-1$ & $-13.21^{* *}(0.02)$ & \\
$\quad$ but own wage did not change & & \\
Tax rate proposed in $t-1$ & $0.36^{* *}(0.00)$ & $0.22^{* *}(0.00)$ \\
Match number & $0.14(0.71)$ & $-0.63^{*}(0.09)$ \\
Risky investment & $-0.005(0.97)$ & $0.16(0.15)$ \\
Constant & $25.01^{* *}(0.01)$ & $35.31^{* *}(0.00)$ \\
\# of observations & 432 & \\
\# of clusters & 48 & 459 \\
Log Likelihood & -1721.28 & -1929.62 \\
\hline \hline
\end{tabular}

Notes: Random effects TOBIT regressions. Dependent variable is Taxes proposed by Poor in match $t$, for $t>1$. Risky investment is a number between 0 and 100 (inclusive), with lower numbers indicating a higher degree of risk aversion. Standard errors are clustered at the individual level. ${ }^{* *}\left({ }^{*}\right)$ indicates significance at $5 \%(10 \%)$ level, and $p$-values are reported in parentheses.

similar in magnitude - on a voter's tax proposal. Second, we observe significant inertia in a voter's tax proposals in both the M2 and M3 treatment, as measured by the coefficient on a voter's $t-1$ tax proposal. Finally, there is no effect of match number or risk attitude for either M2 or M3 treatments, suggesting that other learning effects or degree of risk aversion are not significant factors affecting individual preferences for redistribution.

\section{Conclusions}

We characterize majority-rule equilibrium tax rates in an infinite-horizon model of tax persistence, income mobility, and inequality and implement a two-period version of the model in the laboratory in order to experimentally study the effects of tax persistence and income mobility on the degree of redistribution and post-tax inequality. Our main hypothesis is that if the median voter in the first period has prospects of upward mobility in the second period and tax rates are persistent, then the tax rate will be decreasing in the perceived likelihood of that upward mobility. The experiment varied both the likelihood of income mobility (zero, moderate, high) and the tax regimes, which differ in how often society can adjust tax rates - i.e., persistence of taxes. The results are mostly supportive of the theoretical hypotheses. Indeed, income mobility results in a lower implemented tax rate if tax rates are persistent, but not if tax rates are re-voted every period. Tax persistence leads to lower tax rates and higher inequality. Mobility leads 
to lower inequality without tax persistence and does not affect tax rates. One surprising finding is that increasing mobility from moderate to high actually decreases inequality, in contradiction to the theoretical model. In terms of magnitudes of the observed endogenous variables, we find that tax rates are significantly lower than theoretically predicted and that levels of inequality are significantly higher. We also find that the effects of mobility with tax persistence are considerably larger than theoretically predicted. That is, when people face a possibility of upward mobility and are restricted to choosing the same tax rates in both periods, they tend to enforce levels of redistribution that are lower than the theoretically predicted ones, by a larger amount than is predicted. This effect cannot be attributed to subjects' risk aversion, since risk aversion would push the results in the opposite direction. Our analysis of individual and group behavior suggests that this pattern is partly explained a dynamic learning analysis of the data, the results of which suggest that agents use past observations of experienced mobility to update beliefs about future mobility, even though the stochastic process is time-independent.

Our theoretical and experimental results is a first step toward exploring dynamic models of redistribution in the presence of social mobility. From a theoretical perspective, our approach introduces dynamic considerations into the classic setup of equilibrium taxation and redistribution, by modeling the dynamics as an infinite horizon stochastic game and then characterizing its solution. In the basic model introduced here, a tractable and unique equilibrium is obtained. From a substantive perspective, despite its simplicity, the basic model delivers non-trivial results regarding interaction between tax regime persistence, income mobility, and the underlying distribution of wage inequality in the labor market. Comparative statics results about the effect of these factors on after-tax inequality and efficiency follow naturally. The experimental results confirm the main hypotheses generated by theory. The philosophy behind theory-based experiments is to create simple yet real economic environments, which capture main tradeoffs that economic agents face in such environments, and to observe real subjects making decision with real economic consequences. Our experimental results indicate that the model correctly identifies basic tradeoff that people face in this dynamic environment. The results of the experiment indicate that the theoretical framework developed here is plausible and cannot be dismissed out of hand. Of course, the basic model is very stark and one would like to see the model extended to incorporate other important factors that can affect the dynamics of equilibrium taxes and inequality. One of the stark features of the model is that there is no aggregate uncertainty, so the equilibrium tax rate is the same in all states. There are a number of ways to generalize this, such as incorporating productivity shocks to the 
economy or individual investment in human capital. The model could also be further developed by enriching the model of the political process to include important institutions such as elections and legislatures, and by allowing the tax receipts to be used for public good expenditures as well as pure redistribution. In this way, we are hopeful that framework can be useful as a basis for future theoretical research.

\section{References}

[1] Agranov, Marina and Thomas R. Palfrey. 2015. "Equilibrium Tax Rates and Income Redistribution: A Laboratory Study," Journal of Public Economics, 130: 45-58.

[2] Alesina Alesina, and Eliana La Ferrara. 2005. "Preferences for Redistribution in the Land of Opportunities," Journal of Public Economics, 89(5-6): 897-931.

[3] Benabou, Roland, and Efe Ok. 2001. "Social Mobility and the Demand for Redistribution: The POUM Hypothesis," Quarterly Journal of Economics, 116(2): 447-87.

[4] Charness, Gary, Imas, Alex and Uri Gneezy. 2013. "Experimental methods: Eliciting risk preferences," Journal of Economics Behavior and Organization, 87, 43-51.

[5] Checchi, D. and V. Dardanoni. 2002. "Mobility Comparisons: Does Using Different Measures Matter?," Research on Economic Inequality 9: 113-145.

[6] Checchi, D. and A. Filippin. 2004. "An Experimental Study of the POUM Hypothesis," Research on Economic Inequality 11: 115-36.

[7] Corneo, G. and H. Grüner. 2002. "Individual Preferences for Political Redistribution," Journal of Public Economics, 83: 83-107.

[8] Gneezy, Uri and Jan Potters. 1997. "An experiment on risk taking and evaluation periods," The Quarterly Journal of Economics, 112(2), 631-645.

[9] Konrad, K. and F. Morath. 2011. "Social Mobility and Redistributive Taxation," Working paper \#2011-2, Max Planck Institute for Tax Law and Public Finance, Munich.

[10] Meltzer, A. H., and Richard, S. F. 1981. "A rational theory of the size of government," Journal of Political Economy 89: 914-927.

[11] Piketty, T. 1995. "Social Mobility and Redistributive Politics," Quarterly Journal of Economics 110, 551-84.

[12] Ravallion, M. and M. Loshkin. 2000. "Who Wants to Redistribute? The Tunnel Effect in 1990s Russia," Journal of Public Economics 76(1), 87-104. 
[13] Roberts, K. W. S. 1977. "Voting over income tax schedules," Journal of Public Economics 8, 329-340.

[14] Romer, T. 1975. "Individual welfare, majority voting and the properties of a linear income tax," Journal of Public Economics 4, 163-185.

[15] Rainer, H. and T. Siedler. 2008. "Subjective Income and Employment Expectations and Preferences for Redistribution," Economics Letters, 99(3): 449-453. 


\section{APPENDIX}

\section{Proofs}

Proof of Lemma 1. The maximization problem of an agent $i$ in period $k$ with productivity $w_{i}^{k}$ when tax rate is $t^{k}$ is

$$
\max _{x_{i}^{k}}\left[\left(1-t^{k}\right) \cdot w_{i}^{k} x_{i}^{k}-\frac{1}{2}\left(x_{i}^{k}\right)^{2}+\frac{1}{n} \cdot \sum_{j=1}^{n} t^{k} \cdot w_{j}^{k} x_{j}^{k}\right]
$$

This is a well-defined concave problem with unique solution $x_{i}^{k^{*}}$ which depends only on the tax rate $t^{k}$ and agent own productivity $w_{i}^{k}$

$$
x_{i}^{k^{*}}=\left(1-t^{k}+\frac{t^{k}}{n}\right) w_{i}^{k}
$$

Proof of Proposition 1. To characterize preferences for taxes in period 0 for an agent with productivity $w_{i}$, we need to take into account not only the current productivity of the agent, but his prospects for future productivity. We can think of his current productivity as his current "state", and then look at the transition probabilities to other states. We also have to take account of the possibility that tomorrow the tax rate might change. If it changes, it will change to $t^{*}(p)$, which is the equilibrium tax rate that is derived from solving the dynamic program. Each state will have a continuation value associated with it, denote by $V$, and this generates a system of $n$ equations of the following form:

$$
\begin{aligned}
V_{i}\left(w_{i}, t\right) & =u_{i}^{*}\left(w_{i}, t\right)+\delta p\left[(1-\alpha) V_{i}\left(w_{i}, t\right)+\frac{\alpha}{n} \sum_{j=1}^{n} V_{j}\left(w_{j}, t\right)\right] \\
& +\delta(1-p)\left[(1-\alpha) V_{i}\left(w_{i}, t^{*}(p)\right)+\frac{\alpha}{n} \sum_{j=1}^{n} V_{j}\left(w_{j}, t^{*}(p)\right)\right]
\end{aligned}
$$

where optimal labor supply is given by $x_{i}^{*}\left(w_{i}, t\right)=\left(1-t+\frac{t}{n}\right) \cdot w_{i}$ as shown in Lemma 1 and optimal per-period utility is

$$
u_{i}^{*}\left(w_{i}, t\right)=\frac{w_{i}^{2}}{2} \cdot\left((1-t)^{2}-\frac{t^{2}}{n^{2}}\right)+Z \cdot \frac{t}{n}\left(1-t+\frac{t}{n}\right)
$$

where

$$
Z=\sum_{j=1}^{n} w_{j}^{2}
$$

represents aggregate income of the economy if the tax rate is zero and all workers choose 
labor optimally.

Note that the third term in (8) is a constant with respect to $t$, so we write it as $K\left(w_{i}, t^{*}(p)\right)$. Thus, for each $i=1,2, \ldots, n$ we have the following equation:

$$
(1-\delta p(1-\alpha)) \cdot V_{i}\left(w_{i}, t\right)=u_{i}^{*}\left(w_{i}, t\right)+\frac{\alpha \delta p}{n} \sum_{j=1}^{n} V_{j}\left(w_{j}, t\right)+\delta(1-p) K\left(w_{i}, t^{*}(p)\right)
$$

where

$$
K\left(w_{i}, t^{*}(p)\right)=(1-\alpha) V_{i}\left(w_{i}, t^{*}(p)\right)+\frac{\alpha}{n} \sum_{j=1}^{n} V_{j}\left(w_{j}, t^{*}(p)\right)
$$

Summing these equations across all productivity types and dividing both sides by $n$ :

$$
(1-\delta p(1-\alpha)) \cdot \bar{V}(t)=\bar{u}^{*}(t)+\alpha \delta p \cdot \bar{V}(t)+\delta(1-p) \bar{K}\left(t^{*}(p)\right)
$$

where

$$
\begin{aligned}
\bar{V}(t) & =\frac{1}{n} \sum_{j=1}^{n} V_{j}\left(w_{j}, t\right) \\
\bar{u}^{*}(t) & =\frac{1}{n} \sum_{j=1}^{n} u_{j}^{*}\left(w_{j}, t\right) \\
\bar{K}\left(t^{*}(p)\right) & =\frac{1}{n} \sum_{j=1}^{n} K\left(w_{j}, t^{*}(p)\right)=(1-\alpha) \bar{V}\left(t^{*}(p)\right)+\alpha \bar{V}\left(t^{*}(p)\right)=\bar{V}\left(t^{*}(p)\right)
\end{aligned}
$$

Thus,

$$
\bar{V}(t)=\frac{\bar{u}^{*}(t)}{1-\delta p}+\frac{\delta(1-p)}{1-\delta p} \bar{K}\left(t^{*}(p)\right)
$$

Plugging these expressions into (10) gives us for each $i=1,2, \ldots, n$ :

$$
\begin{aligned}
V_{i}\left(w_{i}, t\right) & =\frac{u_{i}^{*}\left(w_{i}, t\right)}{1-\delta p(1-\alpha)}+\frac{\alpha \delta p \cdot \bar{u}^{*}(t)}{(1-\delta p)(1-\delta p(1-\alpha))}+ \\
& +\frac{\alpha \delta^{2} p(1-p) \bar{K}\left(t^{*}(p)\right)}{(1-\delta p)(1-\delta p(1-\alpha))}+\frac{\delta(1-p) \cdot K\left(w_{i}, t^{*}(p)\right)}{1-\delta p(1-\alpha)}= \\
& =\frac{u_{i}^{*}\left(w_{i}, t\right)}{1-\delta p(1-\alpha)}+\frac{\alpha \delta p \cdot \bar{u}^{*}(t)}{(1-\delta p)(1-\delta p(1-\alpha))}+ \\
& +\frac{\delta(1-p)}{1-\delta p(1-\alpha)} \cdot\left[\frac{\alpha}{1-\delta p} \bar{V}\left(t^{*}(p)\right)+(1-\alpha) V_{i}\left(w_{i}, t^{*}(p)\right)\right]
\end{aligned}
$$

This last expression is just a weighted average between $i$ 's current period utility with productivity $w_{i}$ and the average utility of all types when the tax rate is $t$ plus a constant term that does not depend on $t$. The first-order conditions can be written as 


$$
\begin{gathered}
\frac{\partial V_{i}\left(w_{i}, t\right)}{\partial t}=\frac{1}{1-\delta p(1-\alpha)} \cdot\left[\frac{\partial u_{i}^{*}\left(w_{i}, t\right)}{\partial t}+\frac{\alpha \delta p}{1-\delta p} \cdot \frac{\partial \bar{u}^{*}(t)}{\partial t}\right] \leq 0 \\
\frac{\partial u_{i}^{*}\left(w_{i}, t\right)}{\partial t}=\left(\frac{Z}{n}-w_{i}^{2}\right)-t \cdot \frac{n^{2}-1}{n^{2}} \cdot\left(\frac{2 Z}{n+1}-w_{i}^{2}\right) \\
\bar{u}^{*}(t)=\frac{Z}{2 n}\left((1-t)^{2}-\frac{t^{2}}{n^{2}}\right)+Z \frac{t}{n}\left(1-t+\frac{t}{n}\right) \Rightarrow \frac{\partial \bar{u}^{*}(t)}{\partial t}=-Z \frac{(n-1)^{2}}{n^{3}} \cdot t
\end{gathered}
$$

Then, the first-order condition can be written as

$$
\frac{\partial V_{i}\left(w_{i}, t\right)}{\partial t}=\frac{1}{1-\delta p(1-\alpha)} \cdot\left[\frac{Z}{n}-w_{i}^{2}-t \cdot \frac{n^{2}-1}{n^{2}} \cdot\left(\frac{2 Z}{n+1}-w_{i}^{2}+\frac{\alpha \delta p}{1-\delta p} \cdot \frac{Z(n-1)}{(n+1) n}\right)\right] \leq 0
$$

The second-order condition is

$$
\frac{\partial^{2} V\left(w_{i}, t\right)}{\partial t^{2}}=-\frac{1}{1-\delta p(1-\alpha)} \cdot \frac{n^{2}-1}{n^{2}} \cdot\left(\frac{2 Z}{n+1}-w_{i}^{2}+\frac{\alpha \delta p}{1-\delta p} \cdot \frac{Z(n-1)}{(n+1) n}\right)
$$

When $w_{i}^{2}<\frac{Z}{n}$ we have interior solution because there exists $t^{*} \in(0,1)$ such that

$$
\left.\frac{\partial V_{i}\left(w_{i}, t\right)}{\partial t}\right|_{t=t^{*}}=0 \text { and } \frac{\partial^{2} V_{i}\left(w_{i}, t\right)}{\partial t^{2}}<0
$$

This interior solution is

$$
t_{i}^{*}=\frac{n^{2}}{n^{2}-1} \cdot \frac{\frac{Z}{n}-w_{i}^{2}}{\frac{Z}{n+1}\left(2+\frac{\alpha \delta p}{1-\delta p} \cdot \frac{n-1}{n}\right)-w_{i}^{2}}
$$

When $w_{i}^{2} \in\left[\frac{Z}{n}, \frac{Z}{n+1}\left(2+\frac{\alpha \delta p}{1-\delta p} \cdot \frac{n-1}{n}\right)\right)$, we have $\frac{\partial^{2} V_{i}\left(w_{i}, t\right)}{\partial t^{2}}<0$, thus, max $\frac{\partial V_{i}\left(w_{i}, t\right)}{\partial t}=\left.\frac{\partial V_{i}\left(w_{i}, t\right)}{\partial t}\right|_{t=0}=$ $\frac{1}{1-\delta p(1-\alpha)} \cdot\left(\frac{Z}{n}-w_{i}^{2}\right)<0$, thus $\frac{\partial V_{i}\left(w_{i}, t\right)}{\partial t}<0$ for all $t \in[0,1]$, which means $t^{*}=0$ in this region. Finally, when $w_{i}^{2}>\frac{Z}{n+1}\left(2+\frac{\alpha \delta p}{1-\delta p} \cdot \frac{n-1}{n}\right)$, we have $\frac{\partial^{2} V_{i}\left(w_{i}, t\right)}{\partial t^{2}}>0$ which means that $\max \frac{\partial V_{i}\left(w_{i}, t\right)}{\partial t}=\left.\frac{\partial V_{i}\left(w_{i}, t\right)}{\partial t}\right|_{t=1}<0$, and, therefore, $t^{*}=0$ in this region as well. Combining all the conditions, we obtain

$$
t_{i}^{*}=\left[\begin{array}{ll}
\frac{n^{2}}{n^{2}-1} \cdot \frac{\frac{Z}{n}-w_{i}^{2}}{\frac{Z}{n+1}\left(2+\frac{\alpha \delta p}{1-\delta p} \cdot \frac{n-1}{n}\right)-\left(w_{i}\right)^{2}} & \text { if }\left(w_{i}\right)^{2}<\frac{Z}{n} \\
0 & \text { otherwise }
\end{array}\right.
$$

Proof of Corollary 1. Here we consider the effect of an increase in tax persistence $p$ on equilibrium tax rate when $\left(w_{m}\right)^{2}<\frac{Z}{n}$. 


$$
\frac{\partial t^{*}(p)}{\partial p}=-\frac{n^{2}}{n^{2}-1} \cdot \frac{\left(\frac{Z}{n}-\left(w_{m}\right)^{2}\right)}{\left(\frac{Z}{n+1}\left[2+\frac{\alpha \delta p}{1-\delta p} \cdot \frac{n-1}{n}\right]-w_{m}^{2}\right)^{2}} \cdot \frac{Z}{n+1} \cdot \frac{\alpha \delta(n-1)}{(1-\delta p)^{2} n}<0
$$

Proof of Corollary 2. Next we consider the effect of an increase in $\alpha$ on equilibrium tax rate when $\left(w_{m}\right)^{2}<\frac{Z}{n}$.

$$
\frac{\partial t^{*}(p)}{\partial \alpha}=-\frac{n^{2}}{n^{2}-1} \cdot \frac{\left(\frac{Z}{n}-\left(w_{m}\right)^{2}\right)}{\left(\frac{Z}{n+1}\left[2+\frac{\alpha \delta p}{1-\delta p} \cdot \frac{n-1}{n}\right]-w_{m}^{2}\right)^{2}} \cdot \frac{Z}{n+1} \cdot \frac{\delta p(n-1)}{(1-\delta) n}<0
$$

Proof of Proposition 2. Here we evaluate $\frac{\partial \operatorname{var}\left(V_{i}\left(w_{i}, t^{*}\right)\right)}{\partial p}$ where

$$
\operatorname{var}\left(V_{i}\left(w_{i}, t^{*}\right)\right)=\frac{1}{n} \sum_{j=1}^{n}\left(V_{j}\left(w_{j}, t^{*}\right)-\bar{V}\left(t^{*}\right)\right)^{2}
$$

and $V_{i}\left(w_{i}, t^{*}\right)$ is the long-run income of agent $i$ with productivity $w_{i}$. This exercise is meaningful for $\left(w_{m}\right)^{2}<\frac{Z}{n}$, which guarantees that median agent demands positive tax rates. As we have established in the proof of Proposition $1, V_{i}\left(w_{i}, t^{*}\right)$ can be written as

$V_{i}\left(w_{i}, t^{*}\right)=\frac{u_{i}^{*}\left(w_{i}, t^{*}\right)}{1-\delta p(1-\alpha)}+\frac{\alpha \delta p \cdot \bar{u}^{*}\left(t^{*}\right)}{(1-\delta p)(1-\delta p(1-\alpha))}+\frac{\delta(1-p)}{1-\delta p(1-\alpha)} \cdot\left[\frac{\alpha \bar{V}\left(t^{*}\right)}{1-\delta p}+(1-\alpha) V_{i}\left(w_{i}, t^{*}\right)\right]$

where

$$
\bar{V}\left(t^{*}\right)=\frac{\bar{u}^{*}\left(t^{*}\right)}{1-\delta p}+\frac{\delta(1-p)}{1-\delta p} \cdot \bar{K}\left(t^{*}\right)=\frac{\bar{u}^{*}\left(t^{*}\right)}{1-\delta p}+\frac{\delta(1-p)}{1-\delta p} \cdot \bar{V}\left(t^{*}\right)
$$

Therefore,

$$
\bar{V}\left(t^{*}\right)=\frac{\bar{u}^{*}\left(t^{*}\right)}{1-\delta}
$$

Plugging $\bar{V}\left(t^{*}\right)$ into $V_{i}\left(w_{i}, t^{*}\right)$ and simplifying gives us

$$
\begin{gathered}
V_{i}\left(w_{i}, t^{*}\right)=\frac{u_{i}^{*}\left(w_{i}, t^{*}\right)}{1-\delta(1-\alpha)}+\frac{\alpha \delta \cdot \bar{u}^{*}\left(t^{*}\right)}{(1-\delta)(1-\delta(1-\alpha))} \\
\Rightarrow \operatorname{var}\left(V_{i}\left(w_{i}, t^{*}\right)\right)=\frac{1}{n} \sum_{j=1}^{n}\left(\frac{u_{i}^{*}\left(w_{i}, t^{*}\right)}{1-\delta(1-\alpha)}+\frac{\alpha \delta \cdot \bar{u}^{*}\left(t^{*}\right)}{(1-\delta)(1-\delta(1-\alpha))}-\frac{\bar{u}^{*}\left(t^{*}\right)}{1-\delta}\right)^{2}= \\
=\frac{1}{n(1-\delta(1-\alpha))^{2}} \sum_{j=1}^{n}\left(u_{j}^{*}\left(w_{j}, t^{*}\right)-\bar{u}^{*}\left(t^{*}\right)\right)^{2} \\
u_{i}^{*}\left(w_{i}, t^{*}\right)=\frac{w_{i}^{2}}{2}\left(\left(1-t^{*}\right)^{2}-\frac{\left(t^{*}\right)^{2}}{n^{2}}\right)+Z \cdot \frac{t^{*}}{n}\left(1-t+\frac{t^{*}}{n}\right)
\end{gathered}
$$




$$
\begin{gathered}
\bar{u}^{*}\left(t^{*}\right)=\frac{Z}{2 n}\left(\left(1-t^{*}\right)^{2}-\frac{\left(t^{*}\right)^{2}}{n^{2}}\right)+Z \cdot \frac{t^{*}}{n}\left(1-t^{*}+\frac{t^{*}}{n}\right) \\
\Rightarrow u_{i}^{*}\left(w_{i}, t^{*}\right)-\bar{u}^{*}\left(t^{*}\right)=\left(\left(1-t^{*}\right)^{2}-\frac{\left(t^{*}\right)^{2}}{n^{2}}\right) \frac{w_{i}^{2}-\frac{Z}{n}}{2} \\
\operatorname{var}\left(V_{i}\left(w_{i}, t^{*}\right)\right)=\frac{\left(\left(1-t^{*}\right)^{2}-\frac{\left(t^{*}\right)^{2}}{n^{2}}\right)^{2}}{n(1-\delta+\delta \alpha)^{2}} \sum_{j=1}^{n} \frac{\left(w_{j}^{2}-\frac{Z}{n}\right)^{2}}{4}=\frac{\left(\left(1-t^{*}\right)^{2}-\frac{\left(t^{*}\right)^{2}}{n^{2}}\right)^{2}}{n(1-\delta+\delta \alpha)^{2}} \cdot \psi
\end{gathered}
$$

where $\psi$ is a positive constant term that does not depend on parameters $(\alpha, \delta, p)$. As can be seen from the expression of the variance, the effect of tax persistence on inequality is solely due to change in the equilibrium tax rate $t^{*}$ which is affected by change in $p$. Thus,

$$
\frac{\partial \operatorname{var}\left(V_{i}\left(w_{i}, t^{*}\right)\right)}{\partial p}=\frac{2\left(\left(1-t^{*}\right)^{2}-\frac{\left(t^{*}\right)^{2}}{n^{2}}\right)}{n(1-\delta+\delta \alpha)^{2}} \cdot\left[-2\left(1-t^{*}\right)-\frac{2 t^{*}}{n^{2}}\right] \cdot \frac{\partial t^{*}}{\partial p}>0
$$

since $\frac{\partial t^{*}}{\partial p}<0$ as shown in Corollary 1 . This completes the proof that inequality increases with tax persistence.

Proposition 3. Here we evaluate $\frac{\partial \operatorname{var}\left(V_{i}\left(w_{i}, t^{*}\right)\right)}{\partial \alpha}$ for the interior value of equilibrium tax rate and for each of the two cases described in the proof of Proposition 2. To simplify the exposition, we will write $t$ instead of $t^{*}$ in this section.

$$
\begin{gathered}
\operatorname{var}\left(V_{i}\left(w_{i}, t\right)\right)=\frac{\left(\left(1-t^{*}\right)^{2}-\frac{\left(t^{*}\right)^{2}}{n^{2}}\right)^{2}}{n(1-\delta+\delta \alpha)^{2}} \cdot \psi \\
\frac{\partial \operatorname{var}\left(V_{i}\left(w_{i}, t\right)\right)}{\partial \alpha}=\frac{2 \psi\left((1-t)^{2}-\frac{t^{2}}{n^{2}}\right)}{n(1-\delta+\delta \alpha)^{3}} \cdot\left[\left(-2(1-t)-\frac{2 t}{n^{2}}\right)(1-\delta+\alpha \delta) \frac{\partial t}{\partial \alpha}-\delta\left((1-t)^{2}-\frac{t^{2}}{n^{2}}\right)\right]
\end{gathered}
$$

Denote by $A=\frac{Z}{n}-w_{m}^{2}, B=\frac{2 Z}{n+1}-w_{m}^{2}$ and $C=Z \frac{\delta(n-1)}{n(n+1)(1-\delta p)}$ and re-write equilibrium tax and other expressions using this notation:

$$
\begin{gathered}
t=\frac{n^{2}}{n^{2}-1} \cdot \frac{A}{B+\alpha p \cdot C} \\
\frac{\partial t}{\partial \alpha}=-\frac{n^{2} p \cdot A C}{\left(n^{2}-1\right)(B+\alpha p \cdot C)^{2}} \\
-2(1-t)-\frac{2 t}{n^{2}}=\frac{2 A}{B+\alpha p \cdot C}-2 \\
(1-t)^{2}-\frac{t^{2}}{n^{2}}=1+\frac{n^{2} A(A-2(B+\alpha p \cdot C))}{\left(n^{2}-1\right)(B+\alpha p \cdot C)^{2}}
\end{gathered}
$$


Then,

$$
\begin{aligned}
\left(-2(1-t)-\frac{2 t}{n^{2}}\right) & (1-\delta+\alpha \delta) \frac{\partial t}{\partial \alpha}-\delta\left((1-t)^{2}-\frac{t^{2}}{n^{2}}\right)= \\
& =\frac{2 n^{2} p \cdot A C(1-\delta+\alpha \delta)(-A+B+\alpha p \cdot C)}{\left(n^{2}-1\right)(B+\alpha p \cdot C)^{3}}-\delta\left[1+\frac{n^{2} A(A-2(B+\alpha p \cdot C))}{\left(n^{2}-1\right)(B+\alpha p \cdot C)^{2}}\right]= \\
& =\frac{1}{\left(n^{2}-1\right)(B+\alpha p \cdot C)^{2}} \cdot\left[\frac{2 n^{2} p \cdot A C(1-\delta+\alpha \delta)(-A+B+\alpha p \cdot C)}{B+\alpha p \cdot C}-\right. \\
& =\frac{1}{\left(n^{2}-1\right)(B+\alpha p \cdot C)^{2}} \cdot\left[\left(n^{2}-1\right)(B+\alpha p \cdot C)^{2}+n^{2} A(A-2(B+\alpha p \cdot C))\right)
\end{aligned}
$$

where

$$
\begin{gathered}
\mathbb{K}=\frac{2 n^{2} p \cdot A C(1-\delta+\alpha \delta)(-A+B+\alpha p \cdot C)}{B+\alpha p \cdot C} \\
\mathbb{I}=\delta \cdot\left(\left(n^{2}-1\right)(B+\alpha p \cdot C)^{2}+n^{2} A(A-2(B+\alpha p \cdot C))\right)
\end{gathered}
$$

The next step is to substitute back expressions for $A, B$ and $C$ into $\mathbb{K}$ and $\mathbb{M}$, and characterize shapes of functions $\mathbb{K}(p)$ and $\mathbb{M}(p)$ for $p \in[0,1]$. Provided that $\alpha \in(0,1)$, $\delta \in(0,1),\left(w_{m}\right)^{2}<\frac{Z}{n}$ and $n \geq 3$, we establish that:

- $\mathbb{K}$ is strictly increasing and convex function of $p$ for $p \in[0,1]$

- $\mathbb{M}$ is strictly increasing and convex function of $p$ for $p \in[0,1]$

- $\mathbb{K}_{p=0}<\mathbb{M}_{p=0}$

- $\mathbb{K}_{p=1}>\mathbb{M}_{p=1}$ when $\alpha \in(0,1), Z>\bar{Z}(n, w)$ and $\delta<\bar{\delta}\left(\alpha, Z, n, w_{m}\right)$

- $\mathbb{K}_{p=1}<\mathbb{M}_{p=1}$ otherwise

Therefore, as long as $Z>\bar{Z}\left(n, w_{m}\right)$ and $\delta<\bar{\delta}(\alpha, Z, n)$, there exists a unique $\bar{p}$ such that

$$
\begin{aligned}
& \frac{\partial \operatorname{var}\left(V_{i}\left(w_{i}, t\right)\right)}{\partial \alpha}<0 \text { for } p \in(0, \bar{p}) \\
& \frac{\partial \operatorname{var}\left(V_{i}\left(w_{i}, t\right)\right)}{\partial \alpha}>0 \text { for } p \in(\bar{p}, 1)
\end{aligned}
$$

Otherwise, for all $p \in(0,1)$ we obtain $\frac{\partial \operatorname{var}\left(V_{i}\left(w_{i}, t\right)\right)}{\partial \alpha}<0$. This completes the proof of Proposition 3. 


\section{Instructions}

\section{Sample Instructions for M2 treatment}

Welcome. You are about to participate in an experiment on decision-making and you will be paid for your participation in cash privately at the end of the session. Do not talk to or attempt to communicate with other participants during the session. Please take a minute and turn off all electronic devices, especially phones. During the experiment you are not allowed to open or use any other applications on these laboratory computers, except for the interface of the experiment.

The experiment consists of three parts. Each part is self-contained. Before the beginning of each part, we will read out loud detailed instructions about that part.

The currency in this experiment is called points. All payoffs are denominated in this currency. Points that you earn during the experiment will be converted into US dollars. We will sum up your earnings in all three parts of the experiment, add a $\$ 7$ participation fee for the completion of the experiment and pay it to you in private in cash at the end of the experiment. The money you earn will depend on your decisions and the decisions of others.

Part I. In this part of the experiment you are endowed with 100 points. Your task is to choose how many points you wish to invest in a risky project. You can choose any number of points between 0 and 100 points, inclusive. Those points not invested are yours to keep.

The Risky Project: there is a $50 \%$ chance that the risky project will be successful. If it is successful, you receive 2.2 times the amount you chose to invest. If the project is unsuccessful, you lose the amount invested. To determine if the project is successful or not the computer will flip a computerized fair coin. If the coin will land on heads then the project is successful and if it will land on tails then project is unsuccessful.

Example: Say you invested $X$ out of 100 points in the risky project, where $\mathrm{X}$ represents your choice. (Recall, it can be any number between 0 and 100, inclusive.) Then, with probability $50 \%$ you will receive $(100-X)+2.2 * X$ points and with probability $50 \%$ you will receive $(100-X)+2.2 * 0=100-X$ points.

In this part of the experiment 50 points $=\$ 1$. Your earnings in this task will be added to your earnings in the next part of the experiment.

Please write down the station number you are sitting in:

Please write down how many points you want to invest in the risky project:

(this can be any number between 0 and 100)

Part II. There will be 10 rounds in this part of the experiment. Before the first round begins, all participants will be randomly divided into groups of 5 participants each. In addition, each participant will be assigned a value $V$. There are two possible values of $V$ : $V=5$ and $V=10$. We have 25 participants in this experiment: fifteen participants will be assigned value of $V=5$ and ten participants will be assigned value of $V=10$. In all groups, there will be three members with $\mathrm{V}=5$ and two members with $V=10$.

Your group assignment and your assigned value $\mathrm{V}$ will stay the same for all 10 rounds of Part II. The computer does these assignments randomly. Your assigned value will be 
displayed on your computer screen.

Your task in each round is to choose an investment level. Your investment can be any number between 0 and 15 (up to two decimal places). If you choose investment $X$ and your value is $V$, this will generate your total investment earnings equal to $V \cdot X$. For example, if $V=10$ and $X=4$, then your total investment earnings in that round are computed by $10 * 4=40$ points.

However, investment is not free. The cost to you of investing $X$ is equal to $0.5 \cdot X^{2}$. In the example just given, the investment of $X=4$ costs you 8 points. These costs are subtracted from your earnings at the end of the round.

A portion of your investment earnings for the round will be taxed. If the tax rate is $T \%$, then your taxes will equal $T \%$ of your investment earnings, and you will keep the remaining $(100-T) \%$ of your investment earnings. The amount you keep after taxes is called your after tax investment earnings. Recall the example just given, where $V=10$ and $X=4$, and your total investment earnings is 40 points. If the tax rate is $50 \%$ then your taxes equal 20 points and your after tax investment earnings, which are yours to keep, equal 20 points.

The taxes everyone in your group pays are not thrown away. Rather, the total taxes collected from all members of your group are rebated to the group members in equal shares at the end of each round. For example, if the total amount collected as taxes from all members of the group equals 100 points, then each member will receive back one fifth of this amount, or 20 points. Note that all members of the group are taxed at the same tax rate in a round, and all group members share equally the total taxes collected in the group.

To summarize, your total earnings in a round depend on the value $V$ assigned to you at the beginning of round 1 , your investment $X$, tax rate $T$ and the tax rebate, which is determined by the total taxes collected from all members in your group. Your total earnings in a round consist of three parts:

Total Earnings = Your After Tax Investment Earnings - Your Cost of Investment + Tax Rebate

- After-Tax Earnings $=(1-T) \%$ of $V \cdot X$

- Cost of Investment $=0.5 \cdot X^{2}$

- Tax Rebate $=\frac{1}{5} \cdot$ Taxes collected in your group

- Taxes collected in your group $=T$-Investment Earnings of $1+T \cdot$ Investment Earnings of $2+T$.Investment Earnings of $3+T \cdot$ Investment Earnings of $4+T \cdot$ Investment Earnings of 5

Thus, your total earnings for the round in this example would be equal to $20-8+20=$ 32 points.

At the beginning of each round a tax rate $T$ will be displayed on your screen. This tax rate is the same for all members in your group. However, your group's tax rate may change from round to round. After observing your group's tax rate, you and all other members of your group will be asked to independently choose your investment levels, which can be any non-negative number between 0 and 15 up to two decimal places. 
The screen has a calculator to assist you in deciding how much to invest in each round. The calculator calculates hypothetical earnings for each of the two possible values that your group members have $(V=5$ and $V=10)$. In particular, this calculator calculates your hypothetical earnings in different scenarios.

Here is how the calculator works. In the first row of the calculator, you need to choose value for which you would like to calculate hypothetical earnings. There is a drop-down menu with two options $V=5$ and $V=10$. The second row of the calculator displays your group's tax rate. In the third row of the calculator, you need to enter a hypothetical investment level and a hypothetical amount of total taxes from the other four members of your group in the fourth row. The last row (the fifth one) then displays total earnings of a member with chosen value if those hypothetical amounts were the actual amounts in that round. You can use the up and down buttons to try calculate payoffs in different hypothetical scenarios. (If you enter these manually instead of using the buttons, you will need to press "Enter" for the calculator to work.) The numbers you enter in the calculator are just hypothetical and do not affect yours or someone else's actual earnings. Remember that your and everyone's else tax rebate consist of one fifth of the taxes collected from one own investment earnings and one fifth of the taxes collected from the other group members.

After everyone has entered their investment decision and clicked on the "Submit" button the computer will display your investment decision as well as the investment decisions made by the all other members of your group. It will appear in a table that also shows their values. All of your own information is highlighted in Red on the table. It will also show your earnings for the round, in points, broken down into its three components: after tax investment income, cost of investment, and tax rebate. All of this information is also summarized at the bottom of your screen in the history panel. The history panel will keep track of everything that has happened in your group in all rounds, highlighting your own information in red.

When round 1 is finished, we will move on directly to the next round. The next round will be identical to the previous round except your group's new tax rate $T$ will be posted on your screen.

At the end of Part II, we will sum up all the points that you earned in all 10 rounds of Part II and will convert them into US dollars using the rate 40 points $=\$ 1$. Summary:

- There are 10 rounds in this part of the experiment.

- At the beginning of the first round, each participant is assigned one of the two possible values: fifteen participants get value $V=5$ and ten participants get value $V=10$.

- Also, at the beginning of the first round, participants are randomly matched into groups of five members each with three members with value $V=5$ and two members with $V=10$.

- Group assignment and value assignment stays the same for the whole duration of this part of the experiment. 
- At the beginning of each round, all members of the group observe the tax rate for this round.

- After that, all group members are asked to choose an investment level (number between 0 and 15 with up to two decimal places).

- After that, decisions and earnings for that round are displayed on your screen and recorded in the history panel.

Part III. Part III of the experiment consists of 10 matches, and each match consists of 2 rounds. The group assignments do not change. They are exactly the same as in Part II and you will remain in the same group in all rounds of all matches in Part III.

In the first round of all 10 matches, you will have the same value that you had in Part II of the experiment. Your value in the second round of a match may be the same or may be different from the one you had in the first round. It is determined as follows: with probability $40 \%$ your value in the second round of a match will be the same as your value in the first. However, with probability $60 \%$ the computer will randomly assign values between the members of your group, so that there are still three members with value $V=5$ and two members with value $V=10$. In other words, if you have value $V=5$ in the first round, then with probability $40 \%+60 \% \cdot \frac{3}{5}=76 \%$ you will keep $V=5$ in the second round and with probability $60 \% \cdot \frac{2}{5}=24 \%$ you will get the new value of $V=10$ for the second period. If, on the other hand, you have value $V=10$ in the first round, then with probability $40 \%+60 \% \cdot \frac{2}{5}=64 \%$ you will keep $V=10$ in the second round and with probability $60 \% \cdot \frac{3}{5}=36 \%$ you will get the new value of $V=5$ for the second round. Your value in each round of each match will be clearly displayed on the computer screen.

Each round in Part III is similar to Part II, except that in each match at the beginning of the first round all members of the group are asked to submit a proposal for the tax rate $\mathrm{T}$.

While you are deciding what tax rate you wish to propose, the screen has a calculator to assist you in deciding. You can calculate hypothetical earnings for a round as follows. First choose from the drop-down menu for which value you are calculating hypothetical earnings. In the second row, enter a hypothetical group tax rate. In the third row, enter a hypothetical investment decision of the member with the value chosen by you in the first row. Finally, in the fourth row, enter a hypothetical total taxes amount from the other four members of your group. You can use the up and down buttons to try different hypothetical levels. The fifth (and the last) row then displays what would be total earnings for the chosen member in a round if those hypothetical amounts were the actual amounts. (If you enter these manually instead of using the buttons, you will need to press "Enter" for the calculator to work.) The numbers you enter in the calculator are just hypothetical and do not affect your actual earnings.

After each member of your group has submitted a proposed tax rate, the third highest of the five proposed tax rates is implemented as your group's tax rate in both rounds of this match. The chosen tax rate will be clearly posted on your screen and is the same for everyone in your group. You will then be asked to choose an investment decision (as you did in the Part II of the experiment). Your investment decision can be any number 
between 0 and 15 up to two decimal places. You may use the calculator to explore different hypothetical scenarios, as you did in Part II.

Once everyone in your group have submitted their investments, your payoff for the first round of a match will be determined and we move on to the second round of the current match.

At the beginning of the second round, you will observe your value for the second round, which may be the same as your value in the first round or different. It is determined based on the mechanism described above. Then you will be reminded of the tax rate chosen by your group in the first round. After that you will be prompted to choose your investment level. After all members of your group choose their investment level, you will observe your earnings in the second round.

After the first match is over, we will move on to the second match, in which you will first observe your value for the first round and then will be asked to submit a proposal for the tax rate for your group. The third highest proposal will be implemented as your group tax rate in both rounds of a match.

To remind you, as before, your earnings in each round depend on your value, your chosen investment $X$, tax rate $T$ and the tax return, which is determined by the total taxes collected from all members in your group.

Total Earnings $=$ Your After Tax Investment Earnings - Your Cost of Investment + Tax Rebate

- After-Tax Earnings $=(1-T) \%$ of $V \cdot X$

- Cost of Investment $=0.5 \cdot X^{2}$

- Tax Rebate $=\frac{1}{5} \cdot$ Taxes collected in your group

- Taxes collected in your group $=T$. Investment Earnings of $1+T$. Investment Earnings of $2+T \cdot$ Investment Earnings of $3+T \cdot$ Investment Earnings of $4+T \cdot$ Investment Earnings of 5

At the end of Part III, we will sum up all the points that you earned in all 10 matches of Part III and will convert them into US dollars using the rate 40 points $=\$ 1$. 


\section{Screenshots}
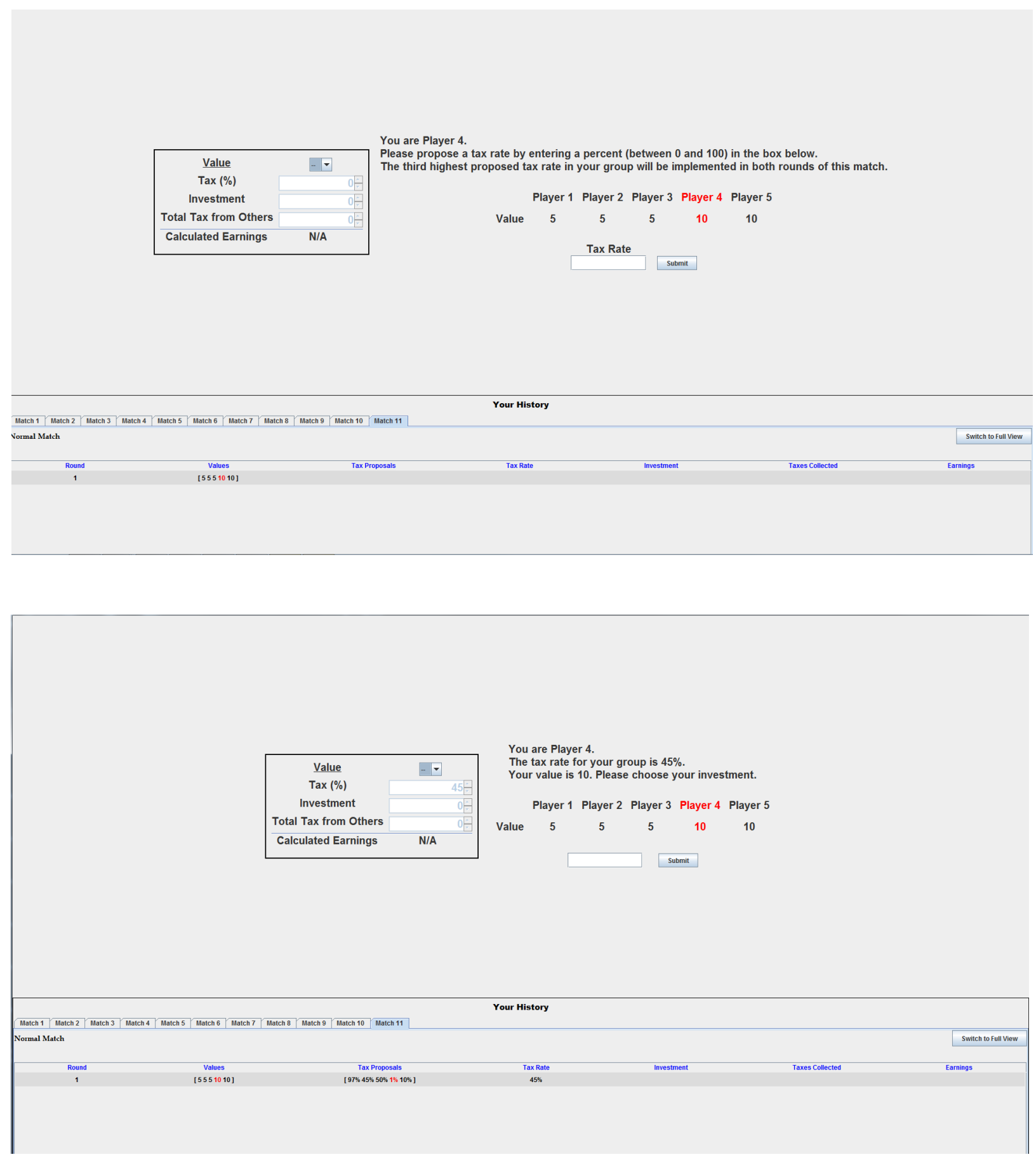


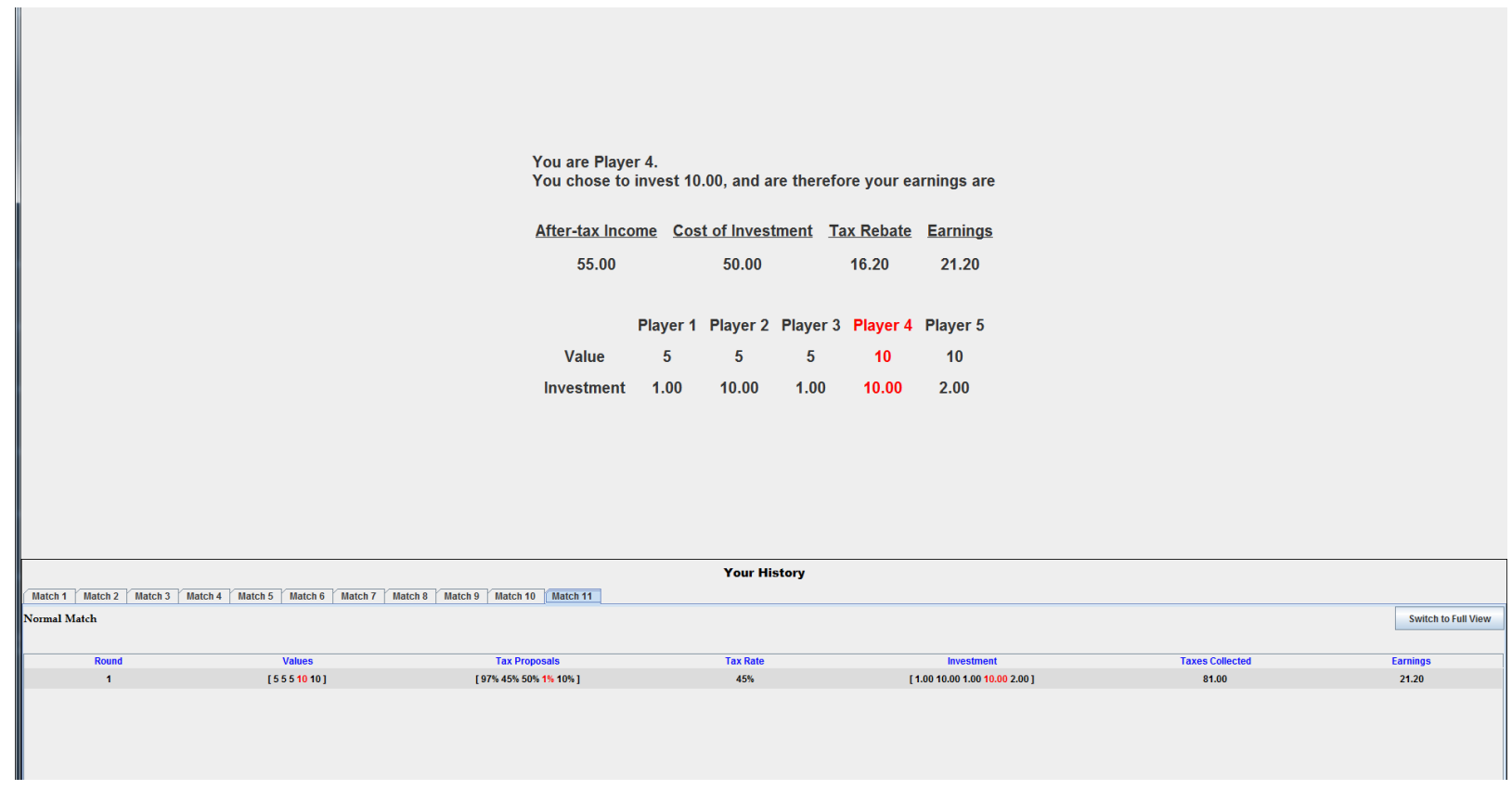




\section{Additional Analysis}

\section{Labor Supply Decisions}

The next two tables, replicate analysis discussed in the main text of the paper using different regression specifications. In particular, Table 7 presents estimates of the normalized labor supply functions for each period of the game separately using the data from all 10 matches of the game. Table 8 pools both periods of the game together, focuses on the experienced matches and clusters standard errors at the individual (rather than at the group) level.

Table 7: Estimated Normalized Labor Supply in Each Period (all 10 matches)

\begin{tabular}{l|cc|cc}
\hline & \multicolumn{2}{|c|}{ NM treatment } & \multicolumn{2}{c}{ M1 treatment } \\
& const (se) & slope (se) & const (se) & slope (se) \\
\hline Poor (period 1) & $0.98(0.02)$ & $-0.73(0.06)$ & $1.02(0.02)$ & $-0.79(0.06)$ \\
Poor (period 2) & $0.99(0.01)$ & $-0.78(0.04)$ & $0.99(0.02)$ & $-0.71(0.05)$ \\
Rich (period 1) & $0.99(0.04)$ & $-0.77(0.07)$ & $1.01(0.03)$ & $-0.84(006)$ \\
Rich (period 2) & $0.96(0.04)$ & $-0.71(0.06)$ & $1.01(0.02)$ & $-0.82(0.06)$ \\
\hline & \multicolumn{2}{|c|}{ M2 treatment } & \multicolumn{2}{c}{ M3 treatment } \\
& const (se) & slope (se) & const (se) & slope (se) \\
\hline Poor (period 1) & $1.00(0.03)$ & $-0.65(0.08)$ & $0.97(0.02)$ & $-0.68(0.07)$ \\
Poor (period 2) & $0.99(0.03)$ & $-0.60^{* *}(0.09)$ & $0.99(0.02)$ & $-0.72(0.06)$ \\
Rich (period 1) & $1.03(0.03)$ & $-0.90(0.06)$ & $0.99(0.01)$ & $-0.75(0.03)$ \\
Rich (period 2) & $0.94^{* *}(0.03)$ & $-0.72(0.09)$ & $0.92^{* *}(0.02)$ & $-0.67(0.07)$ \\
\hline
\end{tabular}

Notes: Random effects TOBIT regressions of normalized labor supply decisions regressed on implemented tax rates and a constant, using data from each of the periods separately. Robust standard errors are clustered at the group level and reported in the parenthesis. Normalized labor supply is labor supply divided by productivity. ${ }^{* *}$ indicates that theoretically predicted value of a coefficient falls outside of $95 \%$ confidence interval of estimated coefficients.

\section{Proposed Taxes}

Figure 3 depicts cumulative distribution functions of tax rates proposed by poor and rich agents in the experienced matches in each treatment separately. Few patterns are apparent from these figures and statistical analysis. First, poor subjects propose higher tax rates than rich subjects in every single treatment. Regression analysis, in which we regress proposed taxes on a dummy variable that indicates rich subject while clustering standard errors by individuals confirms this result at the standard $5 \%$ significance level. Second, poor subjects propose lower tax rates when taxes are persistent as in M2 and M3 treatments compared with treatments in which taxes can be adjusted in every period of the game as in NM and M1 treatments. This can be seen from left panel of Figure 3 as distributions of taxes in NM and M1 treatments first-order stochastically dominates distributions of taxes in M2 and M3 treatments. Regression analysis corroborates this 
Table 8: Estimated Normalized Labor Supply in Experienced Matches

\begin{tabular}{l|cc|cc}
\hline & \multicolumn{2}{|c|}{ NM treatment } & \multicolumn{2}{c}{ M1 treatment } \\
& const (se) & slope (se) & const (se) & slope (se) \\
\hline Poor & $0.96(0.02)$ & $-0.73(0.05)$ & $0.98(0.02)$ & $-0.66^{* *}(0.04)$ \\
Rich & $0.96(0.03)$ & $-0.69(0.06)$ & $0.98(0.02)$ & $-0.77(0.05)$ \\
\hline & \multicolumn{2}{|c|}{ M2 treatment } & \multicolumn{2}{c}{ M3 treatment } \\
& const (se) & slope (se) & const (se) & slope (se) \\
\hline Poor & $1.02(0.02)$ & $-0.76(0.08)$ & $0.98(0.02)$ & $-0.73(0.05)$ \\
Rich & $0.96(0.02)$ & $-0.72(0.08)$ & $0.96(0.02)$ & $-0.76(0.04)$ \\
\hline
\end{tabular}

Notes: Random effects TOBIT regressions of normalized labor supply decisions regressed on implemented tax rates and a constant, using data from each of the periods separately. Robust standard errors are clustered at the subject level and reported in the parenthesis. Normalized labor supply is labor supply divided by productivity. ${ }^{* *}$ indicates that theoretically predicted value of a coefficient falls outside of $95 \%$ confidence interval of estimated coefficients.

conclusion with significant difference detected between average proposed taxes in NM and M2 treatments $(p=0.058)$ and NM versus M3 treatments $(p=0.045)$. The comparison of average taxes between M1 and M2 or M3 treatments are not statistically significant despite first-order stochastically dominance relation.

Figure 3: CDFs of Taxes Proposed by Poor and Rich in Experienced Matches

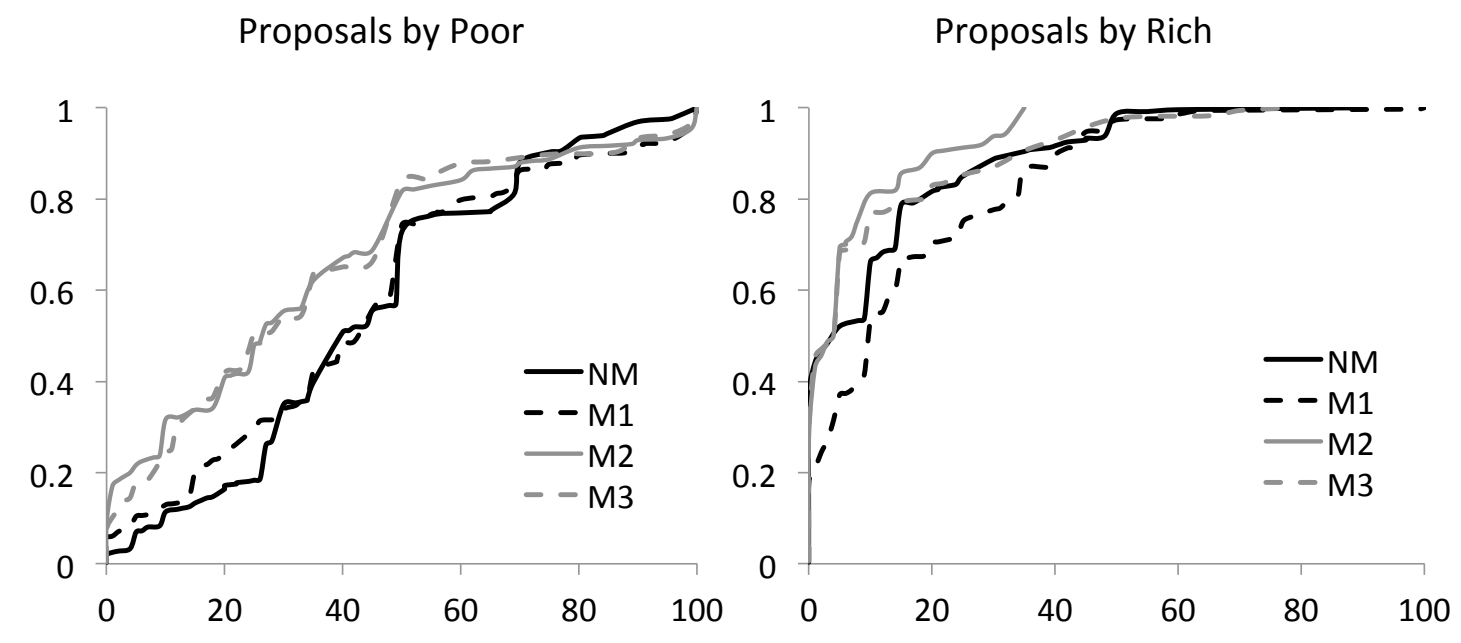

Notes: For NM and M1 treatments, we pool together data from period 1 and period 2 of the game.

\section{Inequality}

Here we consider treatment effects on inequality levels using a GINI coefficient instead of variance of long-run payoffs. Figure 3 depicts cumulative distribution functions of esti- 
mated GINI coefficients across treatments using the data from the experienced matches. To compare GINI coefficients between two treatments we use regression analysis, in which we regress estimated GINI on a constant and a dummy variable that indicates one of the considered treatments, while clustering observations by groups. We conclude that there is a significant difference between two treatments if estimated coefficient on the indicator function is statistically different from zero at the standard $5 \%$ significance level and report p-value associated with it.

Figure 4: CDFs of GINI Coefficients in Experienced Matches

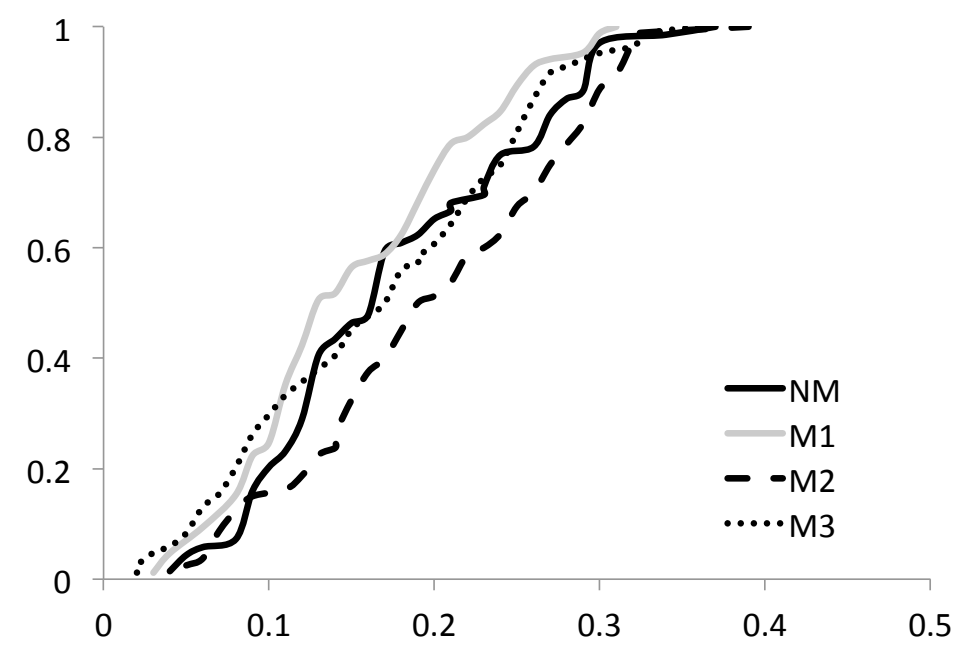

Notes: For NM and M1 treatments, we pool together data from period 1 and period 2 of the game.

Similar to Hypothesis 4 described in the main text of the paper, for parameters used in our experiments, for a given level of mobility, higher tax persistence leads to higher inequality as measured by GINI coefficients. This prediction is born out in our data as the distribution of GINI coefficients observed in M1 treatment first-order stochastically dominates the one observed in M2 treatment, which differ only in the stickiness of the tax regime. Regression analysis confirms prediction this with $p=0.025$.

The same is true for Hypothesis 5, which highlights the differential effect of an increase in mobility on inequality depending on the persistence of tax regime. For parameters in our treatments, when taxes are revoted on in every period, higher mobility promotes equality, while the opposite is true when tax rates are persist from period 1 to period 2. Consistent with this prediction, we observe that inequality decreases when mobility is introduced in the absence of tax persistence (NM versus M1 treatments) albeit the effect is not statistically significant $(p>0.10)$. However, contrary to theoretical prediction, when taxes are persistent, distribution of GINI coefficients observed in M3 treatment first-order stochastically dominates the one in M3 treatment, which indicates that higher mobility promotes equality even when tax regime is sticky. However, this shift is not significant according to regression analysis. 